

B $4 \quad 092 \quad 034$

RATORY GUIDE

Tox TIR

DWSLCHON (F THE CAT

GORHAK AWD TOWER 





Digitized by the Internet Archive in 2007 with funding from Microsoft Corporation 


\section{A LABORATORY GUIDE}

\section{FOR THE \\ DISSECTION OF THE CAT
AN INTRODUCTION TO THE STUDY OF ANATOMY

$\mathrm{BY}$

FREDERIC P. GORHAM, A.M.

RALPH W. TOWER, A.M.

INSTRUCTORS IN BIOLOGY IN BROWN UNIVERSITY

NEW YORK

CHARLES SCRIBNER'S SONS

I 895

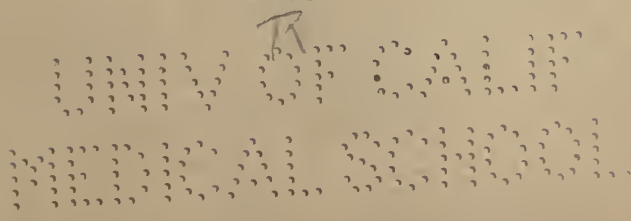


COPYRIGHT, I895, BY

\section{CHARLES SCRIBNER'S SONS}

TROW DIRECTORY

PRINTING ANO BOOKB.NDING COMPANY

$$
\text { NEW YORK }
$$

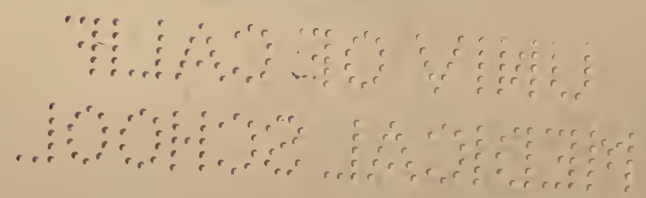




\section{PREFACE}

THis outline has been prepared to supply a convenient laboratory guide for elementary classes in anatomy. It is intended to serve merely as an introduction to anatomical methods and terminology. In its preparation we have been assisted by the suggestions of Dr. H. C. Bumpus, Professor of Comparative Anatomy in Brown University, whose advice we gratefully acknowledge.

\section{BROWN UNIVERSITY,}

April 4, 1895. 



\section{CONTENTS}

INTRODUCTION,

\section{CHAPTER I.-SKELETON.}

Axial Skeleton, . . . . . . . . . 5

A. Skull, . . . . . . . . . . 5

B. Vertebral Column, . . . . . . . 8

C. Ribs, . . . . . . . . . . . . . .

D. Sternum, . . . . . . . . . . IO

Appendicular Skeleton, . . . . . . io

A. Shoulder-girdle and Fore-leg, . . . . . Iо

13. Pelvic-girdle and Hind-leg, . . . . . 12

CHAPTER II.-VISCERA.

Abdominal Viscera, . . . . . . . . I4

A. Alimentary Canal, . . . . . . . . 14

B. Appendicular Organs of the Alimentary Canal, . . I6

C. Urinary System, . $\quad$. $\quad$. $\quad$. $\quad$. . . . 17

D. Reproductive System, . . . . . . I8

THORACIC VISCERA, . . . . . . . . $2 \mathrm{I}$

Viscera of the Head and NeCK, . . . . . 23

A. Salivary Glands, . . . . . . . . 23

B. Mouth, Pharynx, and Larynx, . . . . : 24

CHAPTER III.-MUSCLES.

Muscles of the AbDomen, . . . . . . . 28

Muscles of the Thorax, . . . . . . 30

Muscles of THE FORE-LEG AND Shoulier, . . . 32

MUSCLES OF THE HIND-LEG, . . . . . . 39

MUSClES OF THE NECK, . . . . . . . 42 
CHAPTER IV.-VASCULAR SYSTEM.

ARterial System,

Venous System, .

A. Præ-cava,

$5 \mathrm{I}$

B. Post-cava,

$5 \mathrm{I}$

C. Portal System,

CHAPTER V.-NERVOUS SYSTEM.

Investing Membranes, . . . . . . . 55

External Anatomy of the Brain. . . . . 56

A. Cerebrum, . . . . . . . . 56

B. Cerebellum, . . . . . . . . . 59

C. Medulla Oblongata, . . . . . . . . 60

Internal ANatomy of the Brain, . . . . 61

Distribution of the Cranial Nerves, . . . 65

SPINAL CORD, . . . . . . . . . . 67

SPINAL NeRVES, . . . . . . . . . . 68

A. Brachial Plexus, . . . . . . . . . . 68

B. Lumbar Plexus, . $\quad$. $\quad$. $\quad$. $\quad$. $\quad$. . . 69

Sympathetic System, . . . . . . . 7I

CHAPTER VI.-EYE.

Appendages of the Eye, . . . . . . 73

EYEPALL, . . . . . . • . . . 75

INDEX, . . . . . . . . . . 79 


\section{LIST OF PLATES}

Plate I.-SKEleton, . . . . . . . 12

Plate II.-Superficial Muscles of Right Side, . 28

Plate III.-Deeper Muscles of Right Side, . . 38

Plate IV.-Superficial AND DeEper Muscles of

VENTRAL Side, . . . . . . 44

Plate V.-Arterial System, . . . . . 50

Plate VI.-Venous System, . . . . . . . 54

Plate VII.-Nervous System, . . . . . 72 



\section{INTRODUCTION}

EACH student should be supplied with at least one good scalpel, a pair of strong forceps, a pencil, and a note-book. It is expected that the Laboratory will furnish for general use such necessary equipments as bone-forceps, bone-saws, weighted hooks, and dissecting-boards.

Animals can be conveniently kept from day to day by using ice or by injecting two per cent. formalin into the principal vessels and cavities. For convenience in studying the vascular system, however, the blood-vessels should be injected with some colored fluid. For this purpose an ordinary starch injection mass, prepared according to the following formula, may be used: *

Dry starch (laundry) $\ldots \ldots \ldots \ldots \ldots \ldots \ldots \ldots \ldots \ldots \ldots \ldots \ldots \ldots$ I vol. $21 / 2$ per cent. aqueous solution of chloral hydrate........ I vol. 95 per cent. alcohol ....................

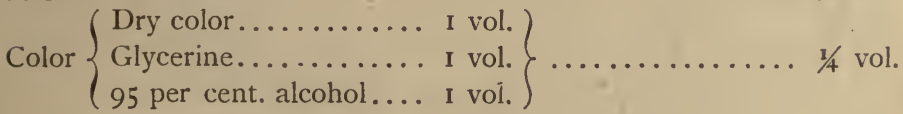

It will be found advisable to immediately remove the brain from such animals as are used for the dissection of the viscera or muscles in order that the organ may be hardened for later dissection. Brains hardened in a two per cent. solution

* See Whitman's “Methods," p. 223. 
of formalin or seventy per cent. alcohol will be found suitable for ordinary dissection. If the formalin or alcohol is injected into the cavities of the brain through the infundibulum, better preparations will be secured. The cat's heart and eye will answer for general dissection, but it will be found convenient to substitute the heart and eye of the pig for more extended study. These can be easily obtained from the slaughter-house. The description here given of the heart and eye of the cat serves equally well for the pig, with the exception that the tapetum is wanting in the latter animal.

Each student should be provided with the unmounted bones of one specimen for the work of the first chapter. Each of the remaining chapters really requires a fresh and complete animal, though with the exercise of considerable care it is possible to study both circulatory and nervous systems from a single specimen. At least three animals, then, are necessary.

Minute directions for dissection often retard the student more than they aid him, and in this guide only the general method is indicated. The ingenuity of the student, directed by the instructor, will suggest the details. For more exhaustive works on the anatomy of the cat, the student is referred to "Anatomical Technology," by Wilder and Gage, and "The Cat," by Mivart.

The figures are diagrammatic, but will serve to 
indicate the more general matters of relative size and position. The nomenclature ordinarily used in standard anatomical literature has been followed. The signification of the general terms of direction is :

Anterior.......toward the head.

Posterior...... . toward the tail.

Dorsal........ toward the region of the back.

Ventral........toward the region of the belly.

Lateral........ toward either side.

Proximal. ..... toward the central axis of the body. Distal........ away from the central axis of the body.

The terms right and left refer to the right and left of the animal being dissected, and not necessarily to the right and left of the dissector. 



\section{CHAPTER I \\ SKELETON}

\section{AXIAL SKELETON}

\section{A.-Skull. (Plate I., A.)}

The Skull is the skeleton of the head and is composed of the following bones:

I. The Occipital Bone, which forms the posterior part of the skull. It surrounds a large opening, the foramen magnum. On either side of this foramen are two smooth articular prominences, the occipital condyles. A projecting ridge on the upper margin of the occipital bone is the lambdoidal ridge. The anterior condyloid foramina pierce the ventral side of the occipital bone a little anterior to the occipital condyles.

2. The Temporal Bones, which form the lateral and posterior part of the base of the skull. On its under surface each presents a prominent oval elevation, the auditory bulla. On the external side of each bulla is a large foramen, the external auditory meatus. Just behind the auditory meatus is a small foramen, the stylo-mastoid. Between each bulla and the occipital bone, just in front of the anterior condyloid foramen, is the, somewhat larger, 
jugular foramen. From the anterior part of the temporal bone extends a bony arch, the zygomatic process. On the under side of this process is a depression for the articulation of the lower jaw, called the glenoid fossa.

3. The Parietal Bones, which form the upper posterior part of the skull. They meet, above, in the median line.

4. The Interparietal Bone, which lies in the middorsal line, between the parietal and occipital bones. It is small and triangular.

5. The Sphenoid Bone, which partially forms the base of the skull. It lies in front of the occipital and between the temporal bones. The sphenoid is pierced on either side by two foramina, the posterior of which is the foramon ovale, the anterior the foramon rotundum.

6. The Presphenoid Bone, which lies in the midventral line, immediately in front of the sphenoid. It is pierced on either side by the optic foramina. Between the sphenoid and presphenoid bones, in line with the optic foramen and the foramen rotundum, is the large sphenoidal fissurc.

7. The Frontal Bones, which form the anterior part of the roof of the skull, meeting above in the mid-line. On either side each frontal bone presents a sharp process, the post-orbital. The cavity behind this process is the temporal fossa.

8. The Malar Bones, which form the outer inferior margin of the orbits. Each articulates pos- 
teriorly with the zygomatic process of the temporal bones.

9. The Maxillary Bones, which form the principal part of the upper jaw. Each bears the following teeth: one canine, three premolars, and one molar. It has a posteriorly-directed process which articulates with the malar bone, and is called the malar process.

IO. The Premaxillary Bones, which are two small bones meeting in the mid-line in front of the maxillary bones. Each bears three incisor teeth.

I I. The Nasal Bones, which lie in the mid-dorsal line above the nasal cavity.

I 2. The Lachrymal Bones, which lie on the anterior walls of the orbits.

13. The Palatine Bones, which form the posterior part of the roof of the mouth.

14. The Vomer, which forms the lower part of the median partition between the nostrils.

I 5. The Ethmoid Bones, which lie between the frontal bones in the nasal chamber. They are composed in part of many folded lamellæ.

I6. The Turbinated Bones, which also consist of folded lamellæ, extending into the nasal chamber, from the inner side of the ethmoid and maxillary bones.

1 7. The Mandible, or skeleton of the lower jaw, which consists of two rami meeting anteriorly in the symphysis. The posterior vertical portion of the mandible is known as the ascending ramus, 
and the remaining portion is the horizontal ramus. The highest point of the ascending ramus is the coronoid process. The mandible bears on either side the following teeth: three incisors, one canine, two premolars, and one molar. (Plate I., B.)

The dental formula would be : i. $\frac{3}{3}$, c. $\frac{1}{1}$, pm. $\frac{3}{2}$, m. $\frac{1}{1}$.

I 8. The Hyoid Arch, which passes from the under side of the skull to the top of the larynx. It is composed of a body and a pair of anterior and posterior horns. The body of the hyoid is formed by a single bone, the basi-hyal, which forms the front part of the upper border of the larynx. Each posterior horn extends around the upper margin of the larynx, and is composed of the thyro-hyal bone. Each anterior horn is composed of the cerato-hyal, epi-hyal, and stylo-hyal bones, and the tympano-hyal cartilage, which unites with the skull. '(Plate I., c.)

\section{B.-Vertebral Column.}

The Vertebral or Spinal Column is composed of seven cervical, thirteen dorsal, seven lumbar, three sacral, and twenty-two caudal vertebræ. Each vertebra is composed of a body and a neural arch enclosing a neural canal and bears on either side a transverse process and dorsally a neural process. Between adjoining vertebræ, on each side, there is 
an intervertebral foramen which permits the passage of blood-vessels and nerves to and from the neural canal.

I. The Cervical Vertebræ form the skeleton of the neck. The most anterior cervical vertebra, the atlas, is somewhat modified to support the skull. It bears on its anterior side two concave articular surfaces which receive the condyles of the skull. Its transverse processes form two wing-like expansions. (Plate-I., D.) The second cervical ver tebra, the axis, is also modified. It bears at its anterior end a pivot, the odontoid process, on which the atlas turns. The odontoid process is morphologically the body of the atlas. (Plate I., E.) Each of the six anterior cervical vertebræ are pierced by two foramina, one on either side of the neural canal.

2. The Dorsal Vertebræ are characterized by the great development of their posteriorly-directed neural processes. (Plate I., G.)

3. The Lumbar Vertebræ are larger, with well-developed transverse processes and anteriorly-directed neural processes. (Plate I., H.)

4. The Sacral Vertebræ are more or less completely united together and serve for the attachment of the pelvis.

5. The Caudal Vertebræ gradually become smaller and their processes reduced. Certain of the caudal vertebræ bear beneath their anterior ventral surface small cheoron bones. (Plate I., I.) 


\section{C.-Ribs.}

The Ribs form the bony framework of the thorax. There are thirteen pairs, articulating dorsally with the vertebral column. The nine anterior pairs or true ribs are connected with the sternum by costal cartilages. The four posterior pairs or false ribs are not united to the sternum. (Plate I., J.)

\section{D.-Sternum.}

The Sternum is the chain of bones forming the ventral support of the cartilages of the ribs. It consists of eight or nine bones (sternebra), of which the most anterior is the manubrium. Posteriorly the sternum ends in the ensiform cartilage, which is more or less expanded and extends freely backward. (Plate I., k.)

\section{APPENDICULAR SKELETON.}

\section{A.--Shoulder-girdle and Fore-leg.}

I. The Clavicle is the small bone which does not articulate with any of the bones of the body, but is imbedded in the muscles of the anterior part of the shoulder. (Plate I., L.)

2. The Scapula or shoulder-blade is the triangular bone which lies against the side of the thorax. Its dorsal edge is the vertebral margin, its ventral edge is the axillary margin. Its outer side is divided by a longitudinal ridge of bone, the spine, 
into a supra- and infra-spinous fossa. Anteriorly the spine bears two processes, the anteriorlydirected acromion process and the posteriorlydirected metacromion process. The concave inner surface of the scapula forms the subscapiular fossa. Anteriorly the scapula ends in a concave articular surface, the glenoid cavity. The corocoid process is a curved projection extending from the anterior edge of the glenoid cavity. (Plate I., м.)

3. The Humerus is the uppermost and largest of the bones of the fore-leg. At its proximal end the humerus has two prominences, of which the outer and larger is the greater tubcrosity, the inner and smaller is the lesser tuberosity. Between the two tuberosities is a rounded surface for articulation with the scapula, known as the head of the humerus. Along the anterior side of the upper part of the shaft of the humerus is a slightly roughened elevation, the deltoid ridge. The supracondyloid foramen is an elongated opening in the lower part of the humerus. The olecranon fossa is a deep depression on the posterior side of the humerus just above its articular surface. (Plate I., N.)

4. The Uina and Radius are the two bones which articulate with the humerus at its distal end. The ulna is the larger and has a prominent process, the olecranon, extending beyond its articulation with the humerus. Below its articulation with the humerus is the smaller coronoid process, which articulates with the radius. (Plate I., o. and P.) 
5. The Carpal Bones are the seven small bones arranged in two tranverse rows below the ulna and radius.

6. The Metacarpals extend distally from the carpals; they are five in number and are considerably elongated.

7. The Phalanges are the bones of the toes. Each toe, with the exception of the innermost or pollex, has three phalanges. The pollex has only two.

\section{B.-Pelvic-girdle and Hind-leg.}

I. The Pelvis is formed by the union of the two innominate bones; it forms a bony arch to which the hind limbs are articulated. The long upper portion of the pelvis, extending from the articulation with the sacrum to the acctabulum, or socket for the articulation of the bone of the thigh, is the ilium. The upper anterior convex border of the ilium is the crest. The portion of the innominate bone extending backward from the acetabulum and forming the upper and hinder margin of a large oval opening, the obturator foramen, is the ischium. The blunt process at the posterior angle of the ischium is the tuberosity. The remaining portion of the innominate bone, extending from the acetabulum toward the mid-ventral line, where it unites with its fellow of the opposite side, is the pubis. The line of union of the two pubes is the symphysis pubis.

(Plate I., Q.) 


$$
\text { • }
$$

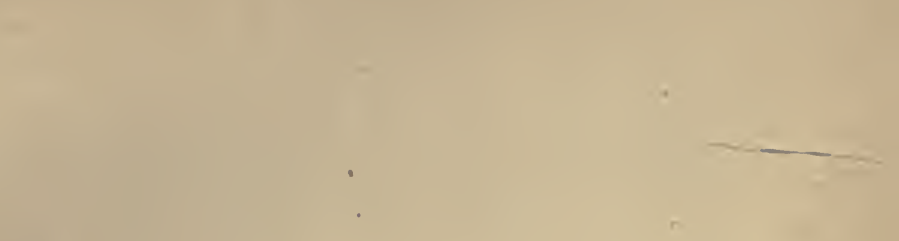

-

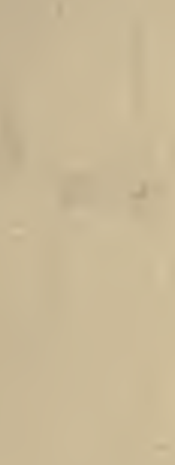

1 


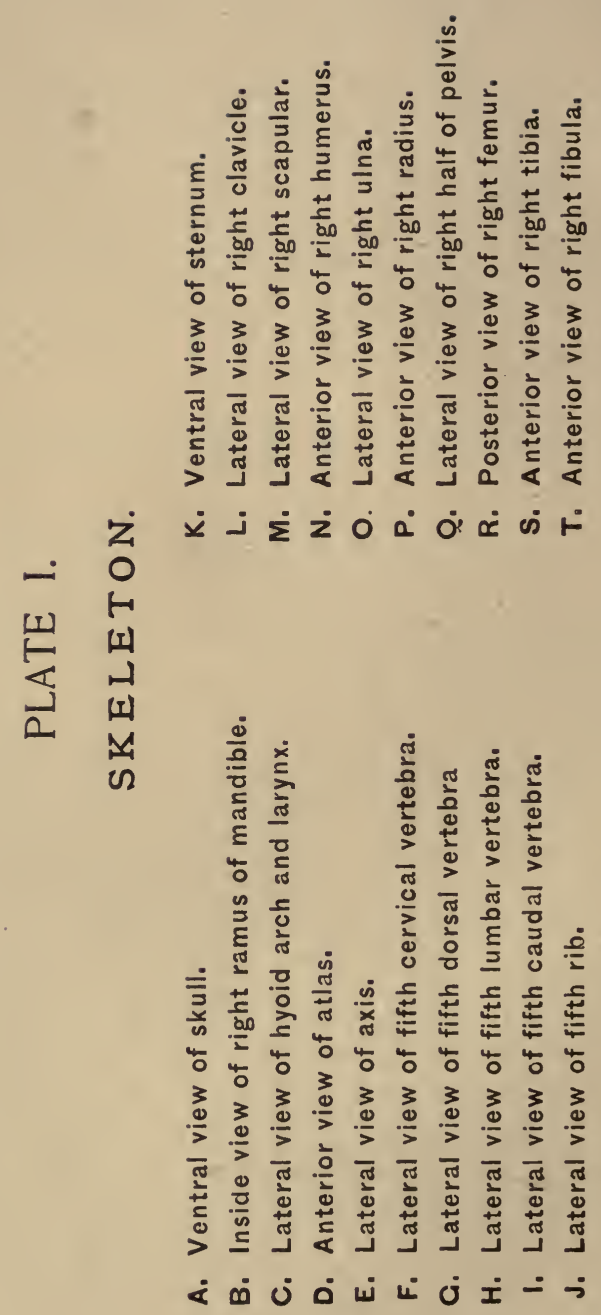








2. The Femur is the bone of the thigh. It has a rounded head, which rests in the acetabulum. External to the head of the femur is a rough elevation, the great trochanter. On the posterior side of the femur is a rough line for the attachment of muscles, the linea aspera. On the posterior side of the lower end of the femur are two rounded articular elevations, the external and internal condyles. The patella or knee-pan is the small oval bone which is imbedded in the tendon on the anterior side of the lower end of the femur. (Plate I., R.)

3. The Tibia and Fibula are the two bones of the leg next below the femur. The tibia is the larger bone, and has at its upper end two articular surfaces which receive the condyles of the femur. On either side of these two surfaces are two projections, the external and internal tuberosities. (Plate I., s and T.)

4. The Tarsal Bones are the seven bones of the ankle. The one with which the tibia articulates is the astragalus. The largest of the tarsal bones, the bone of the heel, is the calcaneum.

5. The Metatarsals are five bones which articulate with the tarsals. The four external ones are long and well-developed; the inner one is very small and rudimentary.

6. The Phalanges are the bones of the toes. There are three in each of the four toes. The innermost metatarsal or hallux has no phalanges. 


\section{CHAPTER II}

\section{VISCERA}

ABDOMINAL VISCERA

Make a median incision through the skin and muscles from the sternum to the symphysis pubis.

I. The Peritoneum is the thin, shining membrane lining the abdominal cavity. It is reflected over the viscera.

2. The Great Omentum is the apron-like fold of the peritoneum which hangs down from the stomach and covers the viscera. It always contains more or less fat.

\section{A.-Alimentary Canal.}

I. The Esophagus passes from the mouth to the stomach. Its posterior end may be seen piercing the diaphragm by pressing aside the lobes of the liver.

2. The Stomach is the enlargement of the alimentary canal immediately posterior to the diaphragm and behind the lobes of the liver.

The Fundus is the portion of the stomach which lies to the left of the entrance of the osophagus. 
The Pylorus is that part of the stomach which opens into the intestine.

The part of the stomach lying to the left is called the cardiac portion; that to the right the pyloric portion; the anterior margin is the lesser curvature; the posterior margin is the greater curvature.

The stomach is lined with mucous membrane, which is thrown into folds at the cardiac end.

3. The Small Intestine is the convoluted tube which leaves the stomach at the pyloric end. The U-shaped portion immediately succeeding the pylorus is the duodenum. The jejunum is the direct continuation which runs a short distance to the right. The remaining convoluted mass is the ileum, which terminates at the junction with the large intestine. The fold of the peritoneum which suspends the intestines from the body wall is the mesentery. Blood-vessels, nerves, and lymphatics pass to the intestine between its two layers.

The mucous membrane which lines the small intestine is raised into a number of closely-set filaments, called villi.

4. The Large Intestine is the remaining large and less convoluted portion of the alimentary canal. It passes forward, from the junction with the ileum, as the ascending colon, across to the left as the transverse colon, and backward as the descending colon, ending in a terminal portion called the 
rectum. The rectum lies in the pelvis and opens to the exterior through the anus. The rounded diverticulum of the large intestine which projects beyond the point where the small intestine opens is the cacum.

The mucous membrane lining the large intestine is smooth throughout.

\section{B.-Appendicular Organs of the Alimentary Canal.}

I. The Pancreas is the long, pinkish body lying in the curve of the duodenum. The pancreas has two ducts opening into the intestine; one in connection with the bile-duct, the other about an inch farther back.

2. The Liver is the large, lobulated, red body lying immediately behind the diaphragm. It is suspended from the diaphragm by a fold of the peritoneum, the falciform ligament, which divides the liver into a right and left portion. These are usually subdivided into the following lobes, but are subject to variation :

a. The right central lobe lies against the right side of the diaphragm. It encloses the gallbladder.

b. The right lateral lobe lies posterior to the right central lobe.

c. The caudate lobe lies on the posterior side of the right lateral lobe and extends backward to the kidney. 
d. The Spigelian lobe is the smallest lobe of the liver. It lies in the mid-line and extends into the small curvature of the stomach.

e. The left central lobe is small and lies against the left side of the diaphragm.

$f$. The left lateral lobe is large and lies between the left central lobe and the stomach.

The gall-bladder is a thin-walled sac which lies in a groove of the right central lobe. Its duct, called the cystic duct, unites with those from the liver and opens into the duodenum in connection with one of the pancreatic ducts.

3. The numerous Lymph Glands are distributed between the layers of the mesentery. Several are found in the angle between the cæcum and the small intestine and are known as the pancreas Asselli.

The anal glands are two oval bodies imbedded in the tissue beneath the skin on either side of the anus.

The Spleen is the long red body lying on the left side, near the stomach. It is suspended in the omentum.

\section{C.--Urinary System.}

I. The Kidneys are the pair of large dark-red bodies of characteristic shape lying on the dorsal wall of the abdominal cavity. On the side of the kidney toward the mid-line there is a marked con- 
cavity or hilus. The kidneys lie outside of the peritoneum.

If the kidney be cut horizontally through its long axis it will be found to consist of two layers, the cortical and the medullary. The outer, cortical portion is of lighter color, the medullary portion is darker and is arranged in a conical mass or pyramid which projects into the cavity or pelvis of the kidney.

2. The Ureter is the tube which passes backward from the hilus of the kidney to the dorsal wall of the bladder.

3. The Bladder is a muscular sac lying near the symphysis pubis. It receives the ureters obliquely in its dorsal surface and opens to the exterior through the urethra.

The Adrenal Bodies are two small whitish bodies which lie internal to the anterior portion of each kidney. They are imbedded in fat.

\section{D.-Reproductive System.}

It will be necessary to cut away the symphysis pubis in order to trace fully the reproductive system.

MALE.

I. The Testes are the essential male organs corresponding to the ovaries of the female. They - are situated in a pouch, the scrotal sac, lying posterior to the symphysis pubis. If the scrotal sac 
is removed, the testes will be seen as two oval bodies enveloped in a sheath of peritoneum, the tunica vaginalis, within which is a white fibrous membrane of connective tissue, the tunica albuginea.

2. The Epididymis is a convoluted mass of tubes which lies external to the tunica albuginea. The enlarged portion at the anterior end is the caput cpididymis; it is connected with the testis by certain ducts. The posterior narrow portion is the cauda cpididymis, which at the posterior end of the testis is continued as the vas deferens.

3. The Vas Deferens is the continuation of the canal of the epididymis ; it passes upward from the testis along with the spermatic artery and vein. These together form the spermatic cord and are enclosed in a common sheath. The vas deferens passes forward through an oblique opening in the abdominal wall, the inguinal canal, bends around the neck of the bladder, and enters the dorsal surface of the urethra to form the urino-genital canal.

4. The Prostate Gland is the glandular mass surrounding the urethra at the point of entrance of the vasa deferentia.

5. Cowper's Glands are the two glands, one on each side of the urino-genital canal, just beyond the prostate.

6. The Penis is the conical pointed organ suspended from the wall of the abdomen by a fold of the integument. It is composed of a median ven- 
tral mass, the corpus spongiosum, and two laterodorsal masses, the corpora cavernosa. It has at its extremity the external orifice of the urino-genital canal. The distal end of the penis is formed by an expansion of the corpus spongiosum, the glans, which is covered by a fold of the integument, the prepuce. The corpora cavernosa diverge anteriorly, forming the crura penis, and are attached to the ischia. In the distal portion of the penis, just over the urino-genital canal, is a small bone, the os penis.

FEMALE.

I. The 0varies are a pair of small, pinkish bodies suspended by a fold of peritoneum from the dorsal wall of the abdominal cavity, just posterior to the kidneys.

2. The Fallopian Tubes are the two small ducts whose fimbriated ends partially grasp the ovaries.

3. The Uterus is formed by the immediate expansion of the Fallopian tubes. It consists of two horns which meet in the mid-line to form the body of the uterus.

4. The Vagina is the posterior continuation of the body of the uterus and opens into the vestibule.

5. The Vestibule or Urino-genital Canal is the canal formed by the union of the urethra and vagina.

6. The Clitoris is a small papilla lying on the ventral wall of the vestibule. It is homologous with the penis of the male. 


\section{THORACIC VISCERA.}

Remove the skin from the anterior part of the thorax, and cut away the ribs and sternum.

I. The Pleuræ are the membranes which line the two sides of the thorax and are reflected over the lungs and great blood-vessels. They meet in the mid-line and form a double-walled septum, the mediastinum. The anterior part contains between its walls the heart and its pericardium. The posterior portion contains the osophagus and blood-vessels.

2. The Lungs are the pinkish lobulated bodies lying on either side in the thoracic cavity. The lungs normally fill the entire thoracic cavity except that part occupied by the heart. When the thorax is opened they are usually found collapsed. The right lung is divided into four lobes and the left into two.

The lungs may be artificially inflated to better demonstrate the lobes.

3. The Trachea may be seen, by pushing aside the heart and lungs, as a cartilaginous, annulated tube. 'This leads from the pharynx to the base of the lungs, where it divides into two bronchi, one of which goes to each lung and there subdivides into numerous smaller bronchi which penetrate the various lobes.

4. The Thymus Gland is the mass of glandular 
tissue which partially invests the trachea just anterior to the heart. It is of large size during immaturity, but atrophies in the adult.

5. The Heart is the muscular organ lying in the centre of the thoracic cavity. From the anterior part all of the great blood-vessels of the body arise. The heart is enclosed in a sac of fibrous tissue called the pericardium; this is filled with a serous fluid. The heart consists of four chambers, the two anterior called auricles, and the two posterior called ventricles.

a. The Right Auricle occupies the anterior ventral portion of the heart. It consists of a main chamber, the atrium, and a lobulated appendage, the auricular appendix. The right auricle receives anteriorly the superior vena cava, which brings back blood from the anterior part of the body, and at its posterior end the inferior vena cava, which returns blood from the posterior part of the body. Between these two openings is the orifice of a small vein which returns blood from the walls of the heart itself, the coronary vein. The right auricle opens into the right ventricle by an aperture which is guarded by three membranous flaps, the tricuspid valve. These flaps are attached to muscular prolongations of the wall of the ventricle, the columice carnece, by tendinous cords, the chorda tendina.

b. The Right Ventricle forms the right ventral portion of the heart. Its cavity is crescentic, with 
much thicker walls than those of the auricle. It receives the blood from the right auricle and pumps it out at its anterior end through the pulmonary artery. The opening of this artery is guarded by three flaps, the semilunar valves.

c. The Left Auricle lies on the anterior dorsal side of the heart. It receives at its dorsal end the pulmonary veins, usually two on each side. The left auricle opens into the left ventricle through an aperture guarded by a valve similar to the tricuspid but with only two flaps, the mitral valve.

d. The Left Ventricle is by far the most muscular portion of the heart. It occupies nearly the whole posterior portion of the organ. Its cavity is oval and receives the blood from the left auricle and forces it out through the aorta, whose opening is guarded by semilunar valves similar to those of the pulmonary artery.

The two coronary arteries which convey blood to the heart itself lead from the aorta just outside of the semilunar valves.

- VISCERA OF THE HEAD AND NECK.

Remove the skin from the head and neck.

\section{A.-Salivary Glands.}

I. The Parotid Gland, the largest of the salivary glands, lies just beneath the skin at the ventral margin of the cartilage of the ear. Its duct, Stenson's duct, may be seen as a fine white canal 
passing across the large oval muscle on the side of the jaw. It penetrates the cheek and opens into the mouth opposite the last premolar tooth.

2. The Submaxillary Gland lies just below the parotid gland at the angle of the mandible, beneath the large jugular vein. It is smaller than the last and oval in shape. Its-duct, Wharton's duct, runs forward beneath the facial vein and opens on the floor of the mouth.

3. The Sublingual Glands, two on either side, lie anterior to the submaxillary gland and closely connected with it, on each side of the jugular vein. They are smaller than the submaxillary but of the same general appearance.

4. The Buccal Glands are a collection of glandular tissue situated at the angle of the mouth.

5. The Zygomatic Gland is situated in the orbit beneath the eyeball just inside the anterior end of the zyoomatic arch. It will be seen if the roof of the mouth be cut through just posterior to the upper molar tooth.

\section{B.-Mouth, Pharynx, and Larynx.}

I. The Hard Palate forms the roof of the mouth. It is covered with mucous membrane which is raised into a number of transverse ridges.

2. The Soft Palate is the posterior continuation of the hard palate. Its free edge hangs like a transverse curtain across the posterior portion of 
the cavity of the mouth, separating the oral and the pharyngeal cavities.

3. The Tonsils lie one on either side of the opening leading from the mouth to the pharynx. They are small oval bodies and are partially embedded by lateral prolongations of the soft palate.

4. The Tongue is a muscular organ attached posteriorly to the hyoid bone and for the greater part of its length to the floor of the mouth. It is covered with a mucous membrane, which is smooth below but above is provided with three kinds of papillæ. The circumvallate papille are the rounded prominences situated in two lines converging posteriorly at the back part of the tongue. The fungiform papille are smaller and more numerous, and are situated on the side and anterior portion of the tongue. The filiform papilla, the most numerous of all, cover the whole of the upper surface of the tongue. They have large, posteriorly-directed, horny points.

5. The Pharynx is the large, conical cavity immediately behind and below the soft palate. It is the posterior continuation of the mouth cavity.

6. The Posterior Nares are two openings into the pharynx, situated just above the palate. They pass forward into the nasal cavity.

7. The Eustachian Tubes are two openings just external to the posterior nares. Their canal places the middle ear in communication with the pharynx. 
Cut away one side of the nasal cavity.

8. The Schneiderian Membrane is the mucous membrane which covers the upper turbinated bones. It is somewhat darker in color than the rest of the nasal membrane, and contains the end organs of the olfactory nerves.

9. The Esophagus is the posterior continuation of the pharynx. It is a collapsed, fleshy tube which passes to the stomach, as already seen.

IO. The Glottis is the slit-like opening situated on the floor of the pharynx. It is guarded by two fleshy folds, the false vocal cords, and by an anteriorly-placed triangular cartilaginous lobe, the epiglottis. This organ completely covers the opening during the act of swallowing. The glottis opens below into the larynx.

I I. The Larynx is the cartilaginous box forming the anterior expanded portion of the trachea. (Plate I., c.) It is composed of the following pieces :

- The epiglottis is the triangular cartilaginous flap covering the glottis anteriorly.

The thyroid cartilage is the largest of all, and forms the anterior border of the larynx.

The arytenoids are the two small cartilages lying one on either side of the mid-line, on the dorsal side just below the thyroid.

The cricoid is the ring-shaped cartilage lying below the arytenoids and thyroid. It has the ap- 
pearance of being the modified uppermost cartilage of the trachea.

I2. The Vocal Cords are two membranous folds lying one on each side immediately below the false vocal cords.

I3. The Trachea is the canal leading posteriorly from the larynx to the lungs, as already seen. It is kept expanded at all times by numerous cartilaginous rings which give it a characteristic appearance. (Plate I., C.)

I4. The Thyroid Glands are two small, reddish bodies situated on either side of the trachea, just posterior to the larynx. 


\section{CHAPTER III}

\section{MUSCLES}

Remove the skin and dissect away the fat and tissue covering the muscles.

A thin layer of muscular fibres covers the neck, thorax, and abdomen, immediately below the skin. The portion upon the neck is known as the platysma myoides. These muscles will be seen as numerous delicate fibres, which remain attached to the skin when it is removed.

\section{MUSCLES OF THE ABDOMEN.}

I. The External Oblique Muscle is a thin, flat muscle, arising by digitations from the eight posterior ribs and the lumbar fascia. Its fibres run obliquely backward toward the mid-ventral line, and end in a thin, broad aponeurosis, which unites with its fellow of the opposite side. A mid-ventral white line, the linea alba, indicates the union of the aponeuroses of the muscles of the two sides. The posterior fibres of the muscle are inserted along the brim of the pelvis. A band of delicate fascia, Poupart's ligament, extends from the symphysis pubis to the anterior part of the ventral margin of the ilium. Between Poupart's ligament and the 
$9^{3}$

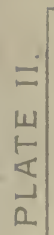

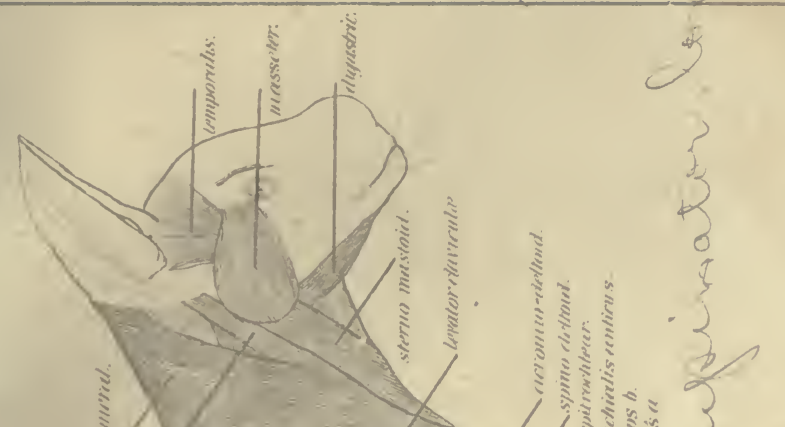



tendon of the external oblique muscle is an aperture, the inguinal canal, through which, in the male, passes the spermatic cord. (Plates II. and IV.)

2. The Internal Oblique Muscle lies immediately under the external oblique, from which it must be separated. It is also a thin, muscular sheet, arising from the lumbar fascia, the ventral margin of the ilium, and the pubis. The fibres run obliquely forward toward the mid-ventral line, where they unite with those of the opposite side in a thin aponeurosis. The more anterior fibres are inserted on the cartilages of the ribs. (Plate III.)

3. The Rectus Abdominis Muscle is a long, narrow muscle, arising from the symphysis pubis. It runs forward, with its fellow of the opposite side, to its insertion on the first, second, and third ribs. The fibres of the rectus abdominis are intercepted at intervals by transverse tendons, making it a true "polygastric muscle." Posteriorly the rectus abdominis muscle lies dorsal to the aponeuroses of the external and internal oblique muscles, but anteriorly it lies between the aponeuroses of these muscles. . (Plates III. and IV.)

4. The Transversalis Abdominis Muscle, the most internal of the abdominal muscles, is a very thin, muscular sheet. It arises from the cartilages of the posterior ribs, the lumbar fascia, and the ventral margin of the ilium. Its fibres run transversely and end in an aponeurosis beneath the rectus abdominis. (Plate IV.) 
5. The Diaphragm is the musculo-tendinous partition separating the abdominal and thoracic cavities. The muscular portion of the diaphragm at its circumference arises ventrally from the ensiform cartilage, laterally from the last five ribs and the aponeuroses of the muscles of the back, and dorsally from the bodies of the lumbar vertebræ by two thick slips or crura. From all these points the fibres converge, to end in the central tendon. 'The diaphragm is pierced by the osophagus, aorta, and inferior vena cava.

\section{MUSCLES OF THE THORAX.}

I. The Pectoralis Muscle is a very large triangular muscle, having its origin on the sternum and the cartilages of the ribs and its insertion on the humerus. It is made up of the following five portions :

a. A long, narrow, superficial division which arises beneath the manubrium and the cartilages of the first two ribs. Part of this is inserted in the fascia of the fore-leg, and part of it joins one of the shoulder muscles, the cephalo-humeral. (Plates III. and IV.)

b. The largest division arises from the manubrium and anterior third of the sternum, and is inserted on the outer side of the deltoid ridge of the humerus. (Plate IV.)

c. Another division arises from the sternum, between the cartilages of the second and sixth ribs. 
It is inserted into the head of the humerus.

(Plate IV.)

d. The posterior division takes its origin from the sternum, between the cartilages of the fifth and eighth ribs, and is inserted principally on the inner side of the deltoid ridge of the humerus.

(Plate IV.)

c. The smallest and most anterior part arises from the side of the manubrium and is inserted on the humerus just above the insertion of $b$, from which it can be separated with difficulty. This division also sends some fibres to the clavicle.

To expose the remaining muscles of the thorax the pectoralis group must be reflected.

2. The Sternalis Muscle is a small triangular muscle arising from the fascia of the rectus abdominis, at the point where the cartilages of the third and fourth ribs unite with the sternum. Its fibres pass forward and outward and are inserted on the first rib. A second, smaller, sternalis muscle lies just outside the rectus abdominis, at the level of the sixth rib. (Plates III. and IV.)

3. The Scalenus Primus Muscle is long and narrow. It takes its origin from the fourth and fifth cervical vertebræ, and is inserted on the cartilages of the fourth, fifth, and sixth ribs. (Plates III. and IV.)

4. The Scalenus Secundus Muscle lies deeper than the last. It takes its origin from the transverse 
processes of the third, fourth, fifth, sixth, and seventh cervical vertebræ, and is inserted on the first rib. (Plates III. and IV.)

5. The External Intercostal Muscles are the outer muscular layers extending between the bony ribs. Their fibres run backward and downward. (Plates III. and IV.)

6. The Internal Intercostals are muscular sheets lying under the former, their fibres running backward and upward. They are covered by the external intercostals, except between the cartilaginous ribs. (Plate III.)

7. The Serratus Posticus Muscle arises from the fascia of the mid-dorsal line, and is inserted by digitations on the eighth, ninth, tenth, eleventh, and twelfth ribs. A dense membrane, the vertebral aponeurosis, is continuous with the muscle anteriorly. This membrane passes forward between the muscles of the back and those of the shoulder, and covers over the crector spince muscles, which fill the groove on either side of the neural processes of the vertebræ. (Plate III.)

\section{MUSCLES OF THE FORE-LEG AND SHOULDER.}

I. The Cephalo-humeral or Anterior Trapezius Muscle takes its origin from the back of the skull and the mid-dorsal line of the neck. It is very long and passes downward, covering the anterior part of the fore-leg, to its insertion on the coronoid proc- 
ess of the ulna. The clavicle is attached to the under side of this muscle, in front of the shoulderjoint. Just before the cephalo-humeral is inserted on the ulna, it receives fibres from the first division of the pectoralis. (Plates II. and IV.)

2. The Middle Trapezius Muscle arises along the mid-dorsal line, immediately posterior to the origin of the cephalo-humeral. Its fibres converge to their insertion upon the spine of the scapula. (Plate II.)

3. The Posterior Trapezius Muscle arises a little posterior to the origin of the middle trapezius, along the mid-dorsal line, above the neural processes of the thoracic vertebræ. It is inserted on the spine of the scapula, above the insertion of the middle trapezius. (Plate II.)

4. The Latissimus Dorsi is the very broad muscle covering a great part of the dorsal portion of the abdomen and thorax. It takes its origin from the neural processes of the last nine dorsal vertebræ, and by fascia from the neural processes of the lumbar vertebræ. Its fibres converge anteriorly, and, blending with the adjacent fibres of the posterior division of the pectoralis muscle, are inserted, together with another muscle, the teres major, by a flat tendon, on the inner side of the shaft of the humerus. The insertion is just below the lesser tuberosity. (Plates II. and IV.)

5. The Cleido-mastoid is a narrow strip of muscle arising from the clavicle and extending to the mastoid process. (Plates II. and IV.) 
Reflect the cephalo-humeral and the middle and posterior trapezius muscles.

6. The Rhomboideus Major is the broad muscle which arises from the neural processes of the six posterior cervical and the anterior dorsal vertebræ. It is inserted on the vertebral margin of the scapula. (Plate III.)

7. The Rhomboideus Capitis is a narrow muscular band lying along the anterior margin of the rhomboideus major. Its origin is on the lambdoidal ridge of the skull and its insertion is on the vertebral margin of the scapula, just in front of the insertion of the rhomboideus major. (Plate III.) (Yevator seapubae ventracis)

8. The Levator Claviculæ is a long, narrow muscle which arises from the transverse process of the atlas, and is inserted on the metacromion process of the scapula. (Plate II.)

9. The Spino-deltoid Muscle takes its origin from the spine of the scapula, opposite the insertion of the middle trapezius muscle. Its fibres run down to unite with those of the following muscle. Both are inserted on the deltoid ridge of the humerus. (Plates II. and III.)

Io. The Acromio-deltoid Muscle is similar in shape to the spino-deltoid muscle. It arises from both the acromion and metacromion processes, and also from the intervening portion of the spine of the scapula. It is inserted, together with the spino- 
deltoid muscle, on the deltoid ridge of the humerus. (Plates II. and III.)

I I. The Epitrochlear is a small muscle, varying in shape, size, and position. It arises partly from the fascia of the scapula, just below the insertion of the posterior trapezius, and partly by muscular fibres from a subjacent muscle, the latissimus dorsi. It is inserted by fascia on the inner side of the alecranon process of the ulna. (Plate II.)

\section{Reflect the deltoid and levator clavicula muscles.}

I 2. The Supraspinatus is the large, thick muscle which fills the entire supraspinous fossa of the scapula and projects considerably over its anterior border. Its fibres originate from the entire fossa, the anterior side of the spine of the scapula, and the acromion process. They are inserted by a strong tendon into the great tuberosity of the humerus. (Plates III. and IV.)

I3. The Infraspinatus Muscle occupies the infraspinous fossa of the scapula. Its fibres arise from the whole fossa, the posterior side of the spine of the scapula, and the acromion and metacromion processes. They converge into a strong tendon, which is inserted on the outer side of the great tuberosity of the humerus, beside the insertion of the supraspinatus muscle. (Plate III.)

I4. The Teres Major is a thick muscle lying along the posterior margin of the scapula. It has its origin on the upper third of the axillary border 
of the scapula, and is inserted, together with the latissimus dorsi, by a flat tendon, on the humerus, just below the lesser tuberosity. (Plates III. and IV.)

I5. The Teres Minor is a much smaller muscle which arises from the lower half of the axillary margin of the scapula, and is inserted on the great tuberosity of the humerus, just below the insertion of the infraspinatus muscle. (Plate III.)

Reflect the latissimus dorsi, rhomboideus major, and rhomboideus capitis muscles.

I6. The Levator Anguli Scapulæ is the thick muscle which takes its origin from the transverse processes of the last five cervical vertebra, and is inserted on the anterior half of the vertebral margin of the scapula. (Plates III. and IV.)

I 7. The Serratus Magnus is the large muscle continuous with the posterior margin of the levator anguli scapulæ. It arises by digitations from the first nine or ten ribs, and is inserted on the posterior half of the vertebral margin of the scapula. The serratus magnus and levator anguli scapulæ form a single sheet of muscle, which suspends the body from the fore-limbs. (Plates III. and IV.)

I8. The Subscapularis is the muscle which fills the entire subscapular fossa. It takes its origin from the greater part of the fossa, from which its fibres converge to their insertion, by tendon, on 
the lesser tuberosity and capsular ligament of the head of the humerus. (Plate IV.)

19. The Coraco-brachialis is a small muscle lying on the inner side of the shoulder-joint and covering the insertion of the subscapularis muscle. It is composed of two parts, both of which arise from the coracoid process of the scapula and are inserted on the inner side of the humerus, just above the insertion of the teres major. (Plate IV.)

20. The Biceps is a long, spindle-shaped muscle, lying on the flexor (anterior) surface of the humerus. It arises by a strong tendon from the anterior margin of the glenoid cavity of the scapula, and is inserted by a similar tendon on the tubercle of the radius. (Plates III. and IV.)

2I. The Brachialis Anticus Muscle lies closely along the outer side of the anterior surface of the humerus, below the insertion of the teres minor. Its fibres converge to their insertion on and near the coronoid process of the ulna. (Plates II. and III.)

22. The Triceps is the large mass of muscle on the extensor (posterior) surface of the humerus. It consists of five parts, as follows :

$a$. The largest division of the triceps arises by a broad tendon from the lower half of the axillary border of the scapula, between the subscapularis and teres minor muscles. It is inserted by a strong tendon on the olecranon process of the ulna. (Plates II., III., and IV.) 
b. The second and most external part arises from the head of the humerus, beneath the insertion of the teres minor. Its fibres pass downward, and are inserted by a tendon on the olecranon process. (Plates II. and III.)

c. The third division arises from the upper part of the shaft of the humerus, below the insertion of the teres major. Its fibres unite with those of the fourth division $(d)$, and are inserted on the olecranon process. (Plates III. and IV.)

d. This division is the most internal, and arises just below the head of the humerus, between the origin of the second division (b) and the insertion of the coraco-brachialis. It passes downward and unites with the third part $(c)$, and both are inserted on the olecranon process. (Plate IV.)

$e$. The smallest part of the triceps arises from the bridge of bone bounding the supracondyloid foramen of the humerus, as far down as the internal condyle. Its fibres pass back to their insertion on the inner side of the olecranon process.

23. The Anconeus Muscle arises from the lower half of the shaft of the humerus, the margins of the olecranon fossa, and the external condyle. Its fibres pass between the second (b) and third (c) parts of the triceps, to their insertion in the fossa just outside the olecranon process.

(Plates II. and III.) 


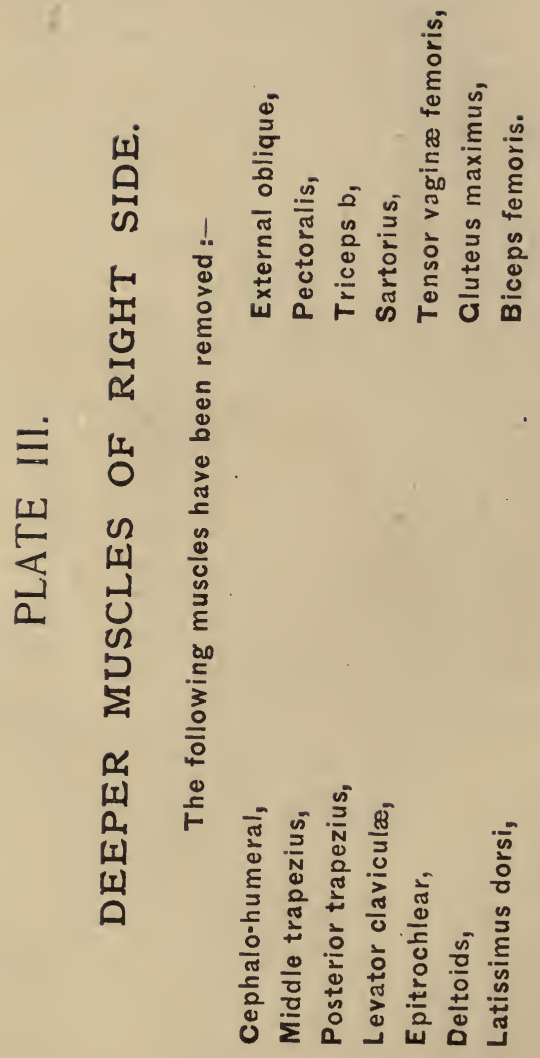




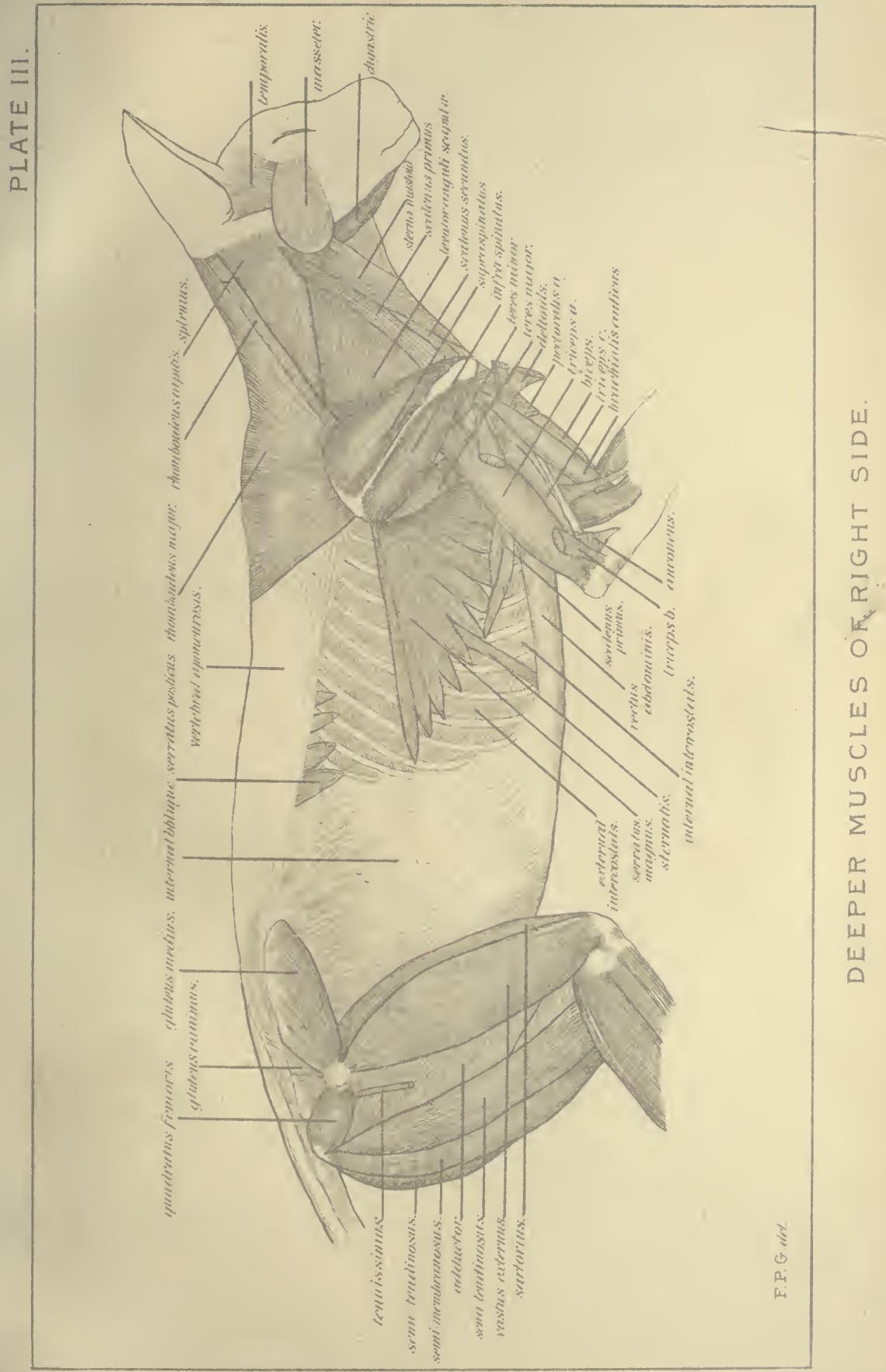





\section{MUSCLES OF THE HIND-LEG.}

I. The Sartorius is a broad, thin muscle which covers the anterior and internal parts of the thigh. It arises from the anterior ventral margin of the ilium, and is inserted both on the ligament of the patella and the internal tuberosity of the tibia. (Plates II., III., and IV.)

2. The Tensor Vaginæ Femoris is a large muscle which arises from the anterior end of the ilium and the adjacent fascia. It is inserted by a strong fascia, which dips in between the muscles, and extends down to the external condyle of the femur. (Plates II. and IV.)

3. The Biceps Femoris is a very large muscle, covering the greater part of the external surface of the thigh. It arises from the tuberosity of the ischium, and is inserted by a strong fascia on the outer side of the tibia, for the greater part of its length. (Plate II.)

4. The Gluteus Maximus is the muscle lying between the biceps femoris and the tensor vaginæ femoris. It arises partly from the sacrum and the fascia covering it dorsally, and partly from the first two caudal vertebra, and is inserted on the great trochanter and shaft of the femur by a sheet of fascia. (Plate II.)

5. The Tenuissimus is a long and very slender muscle which arises from the caudal vertebræ, below the origin of the gluteus maximus. It runs 
along the inner side of the biceps femoris, with which muscle it finally fuses. (Plate III.)

\section{Reflect the preceding muscles.}

6. The Gluteus Medius is a thick muscle lying directly under the gluteus maximus. It arises from the outer surface of the ilium and the fascia, between the gluteus maximus and tensor vaginæ femoris, and is inserted on the great trochanter of the femur.

(Plate III.)

7. The Gluteus Minimus lies directly under the gluteus medius. Its origin is on the ilium, just posterior to the origin of the preceding muscle, and also on the anterior part of the ischium. It is inserted on the great trochanter. (Plate III.)

8. The Quadratus Femoris is the small quadrangular muscle arising from the tuberosity of the ischium. It is inserted on the posterior surface of the femur, near the great trochanter.

(Plate III.)

9. The Semitendinosus is the smaller and more external of the two posterior muscles of the thigh. It arises from the tuberosity of the ischium, and is inserted by fascia on the inner side of the tibia, and by tendon on the front of the tibia, just below the patella. (Plates II., III., and IV.)

IO. The Semimembranosus is the larger of the two posterior muscles of the thigh. Its origin is on the ischium, from the tuberosity to the symphysis pubis. It is inserted (I) on and above the inner condyle of the femur, and (2) by a strong 
tendon on the internal tuberosity of the tibia. (Plates II., III., and IV.)

I I. The Quadriceps Extensor is composed of four large muscles which have separate origins but are inserted on the tuberosity of the tibia by a common tendon, the "tendon of the patella."

a. The vastus externus is the largest and most external of the four divisions. Its origin is on the whole outer surface of the shaft of the femur and on the great trochanter.

(Plate III.)

b. The rectus femoris is the most anterior of the four divisions, lying between the vastus externus and the muscle next to be described, the vastus internus. It arises from the ilium just above the acetabulum. (Plate IV.)

c. The vastus intermus lies between the rectus femoris and the sartorius. It arises from the inner and anterior side of the upper part of the femur. (Plate IV.)

d. The vastus medius, the smallest division, arises from the lower part of the front of the femur. To expose this muscle the three preceding divisions must be reflected.

I 2. The Pyriformis is a small triangular muscle. It arises from the ventral surface of the sacrum, and, passing along the posterior margin of the gluteus minimus, is inserted on the great trochanter of the femur.

I 3. The Gracilis is a broad, thin muscle, covering the greater part of the inner side of the thigh. 
It arises below the symphysis pubis, and is inserted by fascia on the inner side of the tibia, partially beneath the insertion of the sartorius. (Plate IV.)

\section{Reflect the gracilis muscle.}

I4. The Adductor is a large muscle arising from the pubis and ischium, near the symphysis, and below the origin of the gracilis. It is inserted on the posterior part of the femur, along the linea aspera. (Plates III. and IV.)

15. The Pectineus is a small, thin muscle, arising from the pubis, near the symphysis. It is inserted on the ridge between the lesser trochanter and the linea aspera of the femur, and also on the linea aspera itself. (Plate IV.)

i6. The Psoas Magnus is the large, cylindrical muscle lying along the dorsal wall of the abdominal cavity. It arises from the transverse processes of the lumbar vertebræ, and passes out beneath the brim of the pelvis. It is inserted on the lesser trochanter of the femur. (Plate IV.)

\section{MUSCLES OF THE NECK.}

I. The Sterno-mastoid Muscle is a long, narrow band which arises from the side of the manubrium, below the anterior part of the pectoralis major, and is inserted on the skull just above the mastoid process. (Plates II., III., and IV.) 
Reflect the sterno-mastoid muscle.

2. The Sterno-hyoid is a similar muscle, lying beneath the sterno-mastoid, and covering the trachea along the mid-ventral line. It arises on the anterior end of the manubrium, and is inserted on the basi-hyal bone. (Plate IV.)

\section{Reflect the sterno-hyoid muscle.}

3. The Sterno-thyroid is a slender muscle which arises from the anterior end of the manubrium, below the origin of the sterno-hyoid. It is inserted on the thyroid cartilage of the larynx. (Plate IV.)

4. The Digastric is a relatively large muscle, situated at the angle of the mandible. It arises from the skull, posterior to the external auditory meatus, and is inserted along the inner surface of the anterior half of the mandible. (Plates II., III., and IV.)

5. The Genio-hyoid is a small, thin .muscle, lying along the mid-line of the under side of the mandible. It arises near the symphysis, and is inserted on the basi-hyal bone. (Plate IV.)

6. The Mylo-hyoid is the flat muscle forming the floor of the mouth. It arises on the inside of the mandible, and is inserted on the basi-hyal bone. (Plate IV.)

7. The Thyro-hyoid Muscle arises from the thyroid cartilage of the larynx, and is inserted on the 
thyro-hyal bone. It appears to be a continuation of the sterno-thyroid muscle.

8. The Splenius is a large muscle which takes its origin on the mid-dorsal line of the neck and from the neural processes of the anterior dorsal vertebra. It is inserted on the outer part of the lambdoidal ridge of the skull.

(Plate IIİ.)

The Masseter is the thick, oval muscle lying just back of the eye. It arises from the malar bone and from the zygomatic process of the temporal bone, and is inserted on the outer surface of the ascending ramus of the mandible. (Plates II., III., and IV.)

The Temporalis is the fan-shaped muscle covering the side of the skull. It arises from the skull between the lambdoidal ridge and the post-orbital process of the frontal bone. Its fibres converge, filling up the temporal fossa, and are inserted on the coronoid process of the mandible. (Plates II. and III.) 


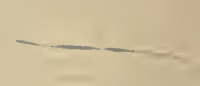

.

1 


\section{PLATE IV.}

\section{SUPERFICIAL AND DEEPER MUSCLES OF VENTRAL SIDE.}

The following muscles have been removed from the left side:-

Genio-hyoid,

Sterno-mastoid,

Sterno-hyoid,

Cleido-mastoid,

Cephalo-humeral,
Pectoralis,

Latissimus dorsi, External oblique, Internal oblique, Sartorius,

Gracilis. 


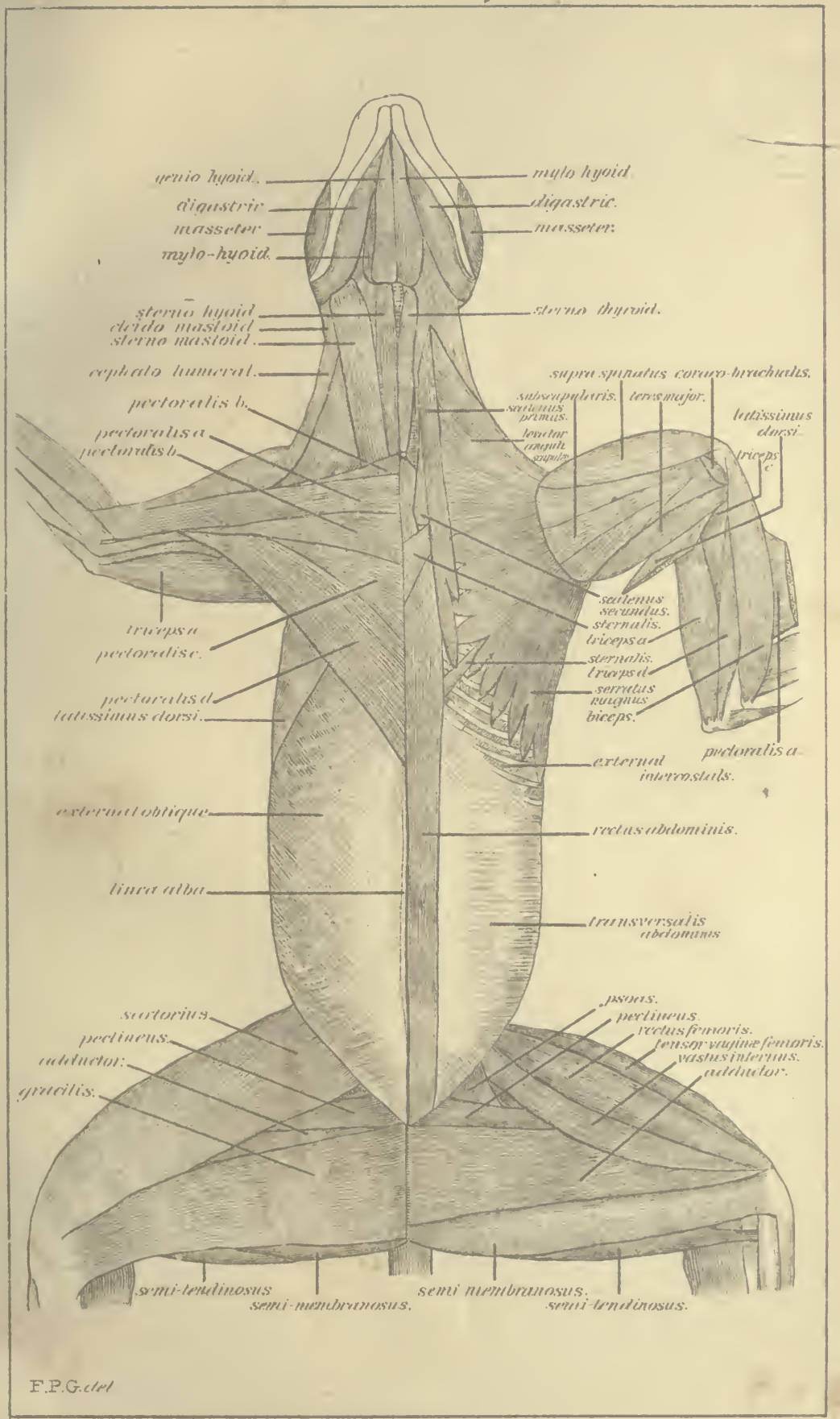

SUPERFICIAL AND DEEPER MUSCLES OF VENTRAL SIDE. 



\section{CHAPTER IV \\ VASCULAR SYSTEM}

\section{ARTERIAL SYSTEM. (Plate V.)}

The Aorta is the large blood-vessel which leaves the left ventricle of the heart and bends in an arch to the left and passes-posteriorly along the midline. It gives off the following branches :

I. The Brachio-cephalic or Innominate Artery is the first and larger of the two branches which lead anteriorly from the arch of the aorta. It soon gives off the following :

a. The Right and Left Carotid Arteries. These pass anteriorly along either side of the trachea and are distributed to the neck and head. Their principal branches are :

(I) The Thyroid Artery, given off at the level of the thyroid gland, and distributed principally to that organ.

(2) A large Muscular Branch, given off directly opposite the thyroid artery, which supplies the muscles of the neck.

(3) The Lingual Artery, which is distributed to the under surface of the tongue.

(4) The Facial Artery, which sends branches to 
the cheek, lips, muscles of the mandible, and to the submaxillary gland.

(5) The Post-auricular Artery, which is distributed to the posterior side of the ear.

(6) The Temporal Artery, which is distributed to the parotid gland and muscles of the side of the head.

After giving off the temporal branch, the carotid passes beneath the masseter muscle and ends in a plexus of small blood-vessels near the glenoid fossa.

b. The Right Subclavian Artery. After giving off the two carotid arteries, the remaining portion of the brachio-cephalic is known as the right subclavian artery. It gives off the following branches :

(I) The Vertebral Artery, which pierces the transverse processes of the six anterior cervical vertebræ, enters the foramen magnum, and unites with its fellow of the opposite side to form the basilar artery of the brain.

(2) The Superior Intercostal Artery, arising a little beyond the vertebral artery, is distributed to the intercostal muscles between the four anterior ribs.

(3) The Sternal or Internal Mammary Artery, given off just beyond the last, runs posteriorly along the inner surface of the sternum.

(4) The Thyroid Axis arises directly opposite the sternal artery, and passes anteriorly and dorsally. It supplies the suprascapular region, and gives off a branch to the thyroid gland. 
(5) The Superior Thoracic Artery, arising a short distance from the thyroid axis, supplies the pectoral muscle.

(6) The Long Thoracic Artery, arising a little beyond the superior thoracic artery, supplies the thoracic muscles.

(7) The Subscapular and Posterior Circumflex Arteries arise from a common trunk, which is given off from the subclavian a little beyond the long thoracic. The subscapular artery supplies the muscles of the subscapular region. The posterior circumflex passes between the subscapular and teres major muscles, and supplies the muscles of the arm.

(8) The Anterior Circumflex Artery, which runs obliquely around the humerus and supplies certain muscles of the arm.

The portion of the subclavian artery between the thyroid axis and circumflex artery is known as the axillary artery. After reaching the arm it becomes the brachial artery.

(9) The Superior and Inferior Profunda Arteries, given off from the brachial, between the shoulder and elbow.

(I0) The Ulnar and Radial Arteries, the two branches into which the brachial divides at the elbow. The radial artery is a direct continuation of the brachial artery, and passes along the flexor surface of the limb to the wrist, where it turns to the dorsal surface, and forms, with a branch of the 
ulnar artery, the palmar arch. The ulnar artery is smaller and less superficial than the radial.

2. The Left Subclavian Artery, unlike the right subclavian, which arises as a branch of the brachiocephalic artery, takes its origin directly from the arch of the aorta. Its branches are similar to those of the right subclavian artery.

3. The Intercostal Arteries arise in ten pairs from the thoracic portion of the aorta and supply all but the first three intercostal spaces.

4. The Bronchial Arteries arise from the aorta near the fourth intercostal artery and supply the lungs.

5. The Phrenic Artery is a small branch given off from the aorta as it pierces the diaphragm, which organ it supplies.

6. The Cœliac Axis is a large branch given off from the aorta after it pierces the diaphragm. It divides into three branches:

a. The Hepatic Artery, which sends branches to the liver, duodenum, and pancreas.

b. The Coronary Artery, which is distributed along the small curvature of the stomach.

c. The Splenic Artery, which supplies the spleen and portions of the stomach.

7. The Superior Mesenteric Artery arises next posterior to the coliac axis. It subdivides in the mesentery and conveys blood to the intestine.

8. The Suprarenal Arteries are two small branches which arise near the superior mesenteric artery and supply the adrenal bodies. 
9. The Renal Arteries are two large arteries which arise one on either side and supply the kidneys.

Io. The Spermatic Arteries, in the male, are two long, slender arteries which arise a little posterior to the renal arteries. They pass backward through the inguinal canal as part of the spermatic cord and supply the testes.

In the female the Ovarian Arteries arise in nearly the same place and supply the ovaries.

I I. The Inferior Mesenteric Artery arises some distance posterior to the last, and is distributed to the lower part of the large intestine and rectum.

I 2. The Ilio-lumbar Arteries are two arteries which arise on either side of the aorta, and supply the muscles of the back.

I3. The External Iliac Arteries are two large arteries given off in the posterior part of the abdominal cavity. They run outward and downward to each hind limb. Before passing Poupart's ligament each gives off a large branch, the obturator artery, which passes through the obturator foramen to the muscles on the back of the pelvis. The obturator artery has a branch, the epigastric artery, which passes forward along the abdominal wall and anastomoses with the internal mammary artery. Each external iliac artery passes beneath Poupart's ligament to reach the thigh, where it becomes the femoral artery. Near its origin each gives off the deep femoral or profunda artery to the muscles of the thigh. At the knee-joint the 
femoral is called the popliteal artery, and, continuing, divides into the anterior and posterior tibial arteries. The posterior tibial artery runs down behind the tibia to the inner side of the os calcis, where it divides into the internal and external plantar arteries. The anterior tibial artery passes along the anterior part of the leg, and becomes the dorsal artery of the foot.

14. The Internal Iliac Arteries are two large lateral branches into which the aorta divides soon after giving off the external iliacs. Each internal iliac gives off a small artery to the bladder, the superior vesical, and then divides into two branches, the pudic and sciatic arteries. The pudic divides into the internal pudic, which is distributed within the pelvis to the genital organs, and the $e x$ ternal pudic, which supplies the external genital organs. The sciatic, after giving off the gluteal, which is distributed to the muscles on the back of the pelvis, passes out through the great sciatic notch, and goes to the muscles of the hip and thigh.

15. The Caudal Artery is the posterior continuation of the aorta. It passes along beneath the tail.

Muscular Branches are given off at various points, both from the aorta and from other arteries to adjacent muscles. 






VENOUS SYSTEM. (Plate VI.)

\section{A.-Præ-cava.}

The Præ-cava, or Superior Vena Cava, is the large vein which brings back blood from the anterior part of the body, and empties into the right auricle, as already described. . It receives the following branches :

I. The Azygos Vein collects the blood from the intercostal and lumbar regions, and empties into the præ-cava in front of the heart.

2. The Vertebral Vein of the right side joins the superior vena cava some distance anterior to the azygos vein.

3. The Sternal Veins enter the præ-cava by a common trunk on its ventral side just anterior to the right vertebral vein. They arise as two veins on either side of the sternum, and, passing anteriorly, unite at the level of the fourth rib.

4. The Brachio-cephalic or Innominate Veins are two large veins which unite at the level of the subclavian arteries to form the præ-cava.

5. The External Jugular Vein is formed by the union of the temporal, internal maxillary, and facial veins, which correspond to the arteries of the same names. It runs just beneath the skin, across the sterno-mastoid muscle, and emptiès into the subclavian vein. Between the temporal and 
facial veins the two external jugular veins are united by a cross branch, the transverse vein.

6. The Internal Jugular Vein returns blood from the brain. It runs parallel to the carotid artery, internal to the external jugular vein and unites with the external jugular vein just before it empties into the brachio-cephalic.

7. 'The Subclavian Vein is the large vessel which returns blood from the fore-leg, where it has branches similar to those of the subclavian artery. It unites with the external jugular vein to form the brachio-cephalic vein.

8. The Left Vertebral Vein returns blood from the cranial cavity. It empties into the left brachiocephalic, between the entrance of the external jugular and the union of the brachio-cephalic veins. 


\section{B.-Post-cava.}

The Post-cava or Inferior Vena Cava is the large rein which returns blood from the posterior part of the body, and empties into the right auricle. It receives its first branch as it pierces the diaphragm.

I. The Phrenic Veins collect blood from the diaphragm, and enter the post-cava just as it pierces that organ.

2. The Hepatic Veins collect the blood from the liver, and empty into the post-cava, near the phrenic veins.

3. The Suprarenal Veins collect the blood from the abdominal walls and adrenal bodies, and usually empty into the post-cava, near the level of the corresponding arteries.

4. The Renal Veins correspond to the arteries of the same name.

5. The Spermatic and Ovarian Veins correspond to the spermatic and ovarian arteries, though usually those of the left side empty into the renal vein instead of the post-cava.

6. The Ilio-lumbar Veins also correspond to the ilio-lumbar arteries.

7. The Common Iliac Veins are two large veins which unite with the caudal vein to form the postcava. They are formed by the union of the internal and external iliac veins, which have a similar distribution to the arteries of the same name. 
8. The Caudal Vein is the direct continuation of the post-cava. It returns blood from the tail.

\section{C.-Portal System.}

The Portal Vein is formed by a number of branches, which collect the blood from the intestines, spleen, pancreas, and stomach. These branches unite within the mesentery. The portal vein enters the under side of the liver, just above the hepatic artery. In the liver it breaks up into capillaries, which again unite, to form the hepatic vein. This vein empties into the post-cava, near the diaphragm, as already described.

The portal system returns blood from the regions supplied by the superior and inferior mesenteric arteries and the coeliac axis. 


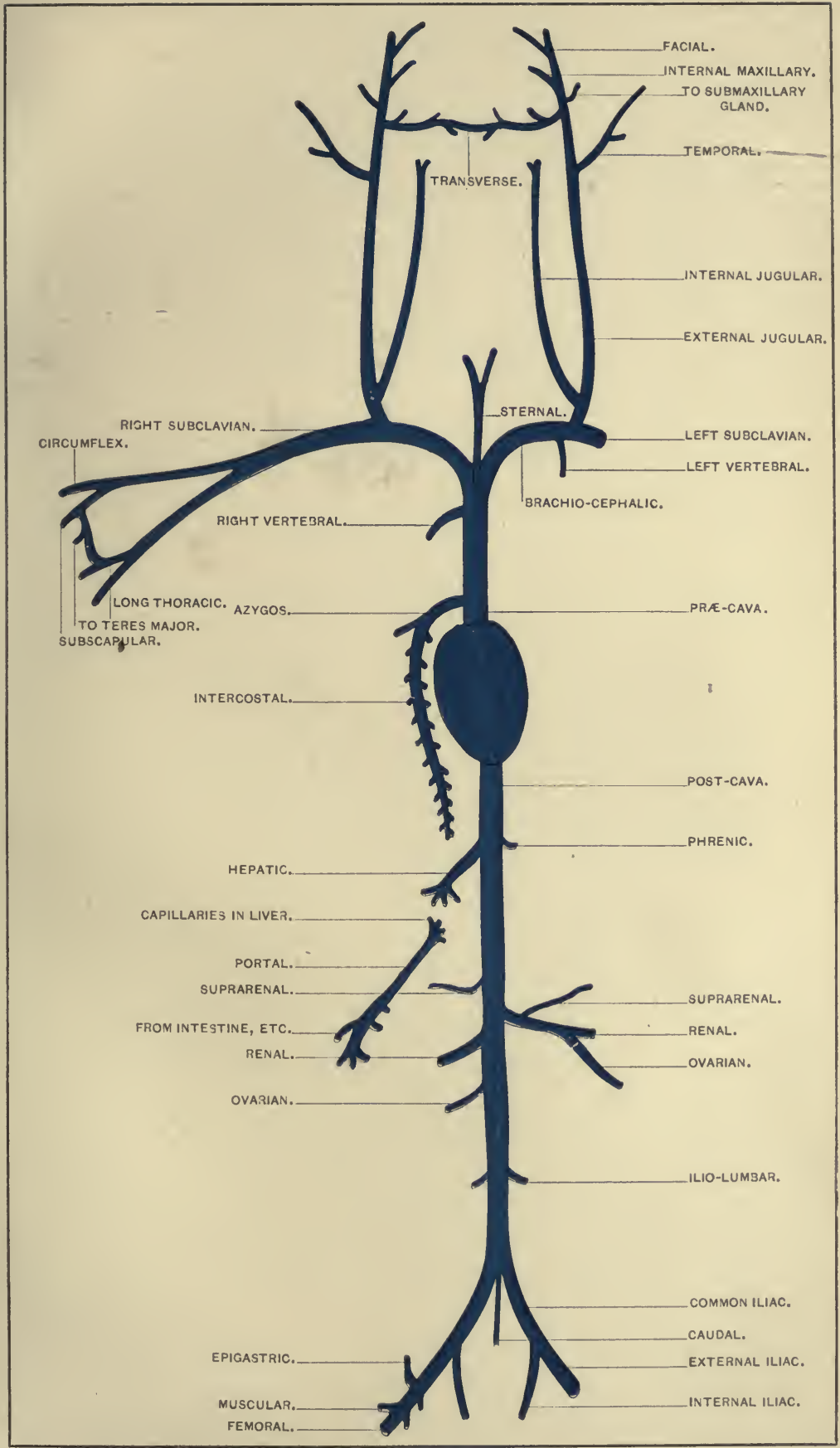





\section{CHAPTER V}

\section{NERVOUS SYSTEM}

INVESTING MEMBRANES.

I. The most external of the three membranes which enclose the brain and spinal cord is the dura mater. It is a thick, fibrous membrane, which lines the inside of the skull and vertebral column. It dips down in a longitudinal fold between the two lobes of the brain forming the falx cerebri. It also makes a transverse fold below the posterior margin of the parietal bone, between the cerebrum and cerebellum. This is called the tentorium, and in adult cats becomes ossified.

2. The most internal membrane, the pia mater, is much thinner and less dense, and closely invests the brain and cord. The blood-vessels supplying the central nervous system are contained in this membrane.

3. The arachnoid is a very delicate membrane, lying between the dura and pia mater. It is closely connected with the dura mater, but does not follow all the folds of the pia mater. It may be seen bridging over the fissures of the brain. 


\section{EXTERNAL ANATOMY OF THE BRAIN.}

The brain is the portion of the nervous system within the cranial cavity. It is divided into three principal parts - the cerebrum, cerebellum, and medulla oblongata.

The cerebrum forms the largest part of the brain, occupying the anterior portion of the cranial cavity. It consists of two lobes or hemispheres.

The cerebellum is the unpaired posterior portion of the brain. It is connected with the rest of the brain by bands of fibres or crura, two of which pass to the cerebrum, two to the medulla, and two blend together below the cerebrum and form the pons Varolii.

The medulla oblongata forms the posterior part of the brain, below the cerebellum. It is continuous posteriorly with the spinal cord.

\section{A.-Cerebrum.}

I. The Cerebrum is the large anterior part of the brain. It consists of two lobes or hemispheres, which are composed of a number of convolutions, or gyri, separated by fissures, or sulci. (Plate VII., $\mathrm{A}, \mathrm{B}$, and C.)

2. The Olfactory Lobes are the two small, knoblike prolongations from the anterior ventral surface of the cerebral hemispheres. (Plate VII., A and c.)

3. The first pair of cranial nerves, the olfactory, arise from the under side of the olfactory lobes. 
4. The Corpus Callosum is the broad white band of fibres connecting the two cerebral hemispheres. It may be seen from the dorsal side by pressing the hemispheres apart. (Plate VII., c.)

5. The Corpora Quadrigemina are the two pairs of rounded elevations which lie on the dorsal surface of the brain, between the cerebrum and cerebellum, which must be pressed apart to expose them. The anterior pair are smaller than the posterior, and are called the nates. The posterior pair are called the testes. (Plate VII., c.)

6. The Pineal Gland is a single rounded prominence, lying in the mid-dorsal line, just anterior to the nates. (Plate VII., c.)

7. The Valve of Vieussens is the delicate membrane covering the cavity of the brain, posterior to the corpora quadrigemina and beneath the anterior portion of the cerebellum. (Plate VII., c.)

8. The second pair of cranial nerves, the Optic, are the large nerves arising from the transverse band of fibres known as the optic chiasma, situated on the ventral side of the brain, just posterior to the fissure separating the two hemispheres. (Plate VII., A and c.)

9. The Optic Chiasma is formed by the crossing of the fibres of the optic tracts which run up beneath the cerebral lobes and over the ventral surface of two oval bodies, the optic thalami, to which they send fibres, and end finally in the corpora quadrigemina. (Plate VII., $\mathrm{A}$ and c.) 
10. The Lamina Cinerea lies just anterior to the optic chiasma. It is a thin membrane, connecting the optic chiasma and corpus callosum, and enclosing a cavity in the brain known as the third ventricle. (Plate VII., c.)

- I I. The Pituitary Body is situated at the end of a conical prolongation of the ventral surface of the brain just posterior to the chiasma. In most cases it is torn off in removing the brain from the skull, leaving nothing but a hollow stalk. (Plate VII., A and C.)

I 2. The Infundibulum is the hollow conical projection which forms the stalk of the pituitary body. The cavity of the infundibulum is continuous with the third ventricle. (Plate VII., c.)

I 3. The Tuber Cinereum is a slight prominence, from which projects the infundibulum. (Plate VII., A.)

I4. The Corpora Albicantia are two small, rounded elevations, just posterior to the tuber cinereum. (Plate VII., A.)

I 5. The Crura Cerebri are two thick bands of fibres which diverge on either side of the corpora albicantia, and pass dorsal to the optic tracts. (Plate VII., A.)

I6. The third pair of cranial nerves, the Oculomotor, emerge in the mid-ventral line, posterior to the corpora albicantia, in the angle between the diverging crura cerebri. (Plate VII., A.)

I 7. The fourth pair of cranial nerves, the Pathetic, 
emerge from the surface of the brain on the outer sides of the crura cerebri.

\section{B.-Cerebellum.}

I. The Cerebellum is the large unpaired portion of the brain lying just posterior to the cerebral hemispheres. The dorsal surface is marked by numerous parallel grooves. It consists of two lateral lobes or hemispheres, and a median portion or acrmis. It is connected with the rest of the brain by three pairs of fibrous bands or crura. The first pair are the superior peduncles. They connect the cerebellum with the corpora quadrigemina. The second and largest pair form the lateral continuations of the pons Varolii. They are known as the middle peduncles. The third pair, the inferior peduncles, connect the cerebellum with the medulla oblongata. (Plate VII., A and c.)

2. The Pons Varolii is the broad, transverse band of fibres on the ventral side of the brain, connecting the two sides of the cerebellum. (Plate VII., A.)

3. The fifth pair of cranial nerves, the Trigeminal, arise by two roots on either side of the pons $\mathrm{Va}$ rolii. (Plate VII., A.)

4. The sixth pair of cranial nerves, the Abducens, leave the surface of the brain at the posterior margin of the pons near the mid-ventral line. (Plate VII., A.)

5. The Anterior Pyramids are the two longitudinal 
bands of fibres, lying on either side of the midventral line, just posterior to the pons. They are a direct continuation of the fibres of the medulla. (Plate VII., A.)

6. The Corpus Trapezoides is a transverse band of fibres, posterior to the pons Varolii, covered, in the mid-line, by the anterior pyramids. (Plate VII., A.)

7. The Olivary Body is the oval elevation just posterior to the corpus trapezoides and lateral to the anterior pyramids. (Plate VII., A.)

8. The seventh pair of cranial nerves, the Facial, leave the surface of the brain at the outer anterior angles of the corpus trapezoides. (Plate VII., A.)

9. The eighth pair of cranial nerves, the Auditory, emerge from the brain at the outer borders of the corpus trapezoides, just posterior to the origin of the seventh. (Plate VII., A.)

\section{C.-Medulla Oblongata.}

I. The Medulla Oblongata is the part of the brain lying posterior to, and below, the cerebellum. It is the expanded anterior portion of the spinal cord, and is composed of a dorsal, a lateral, and a ventral pair of fibrous bundles. (Plate VII., A and C.)

2. The Posterior Pyramids are the two dorsal bundles of fibres, lying one on either side of the median fissure. Anteriorly they blend with the restiform bodies. 
3. The Restiform Bodies are the slightly enlarged portions of the medulla which form the connection between the posterior pyramids and the inferior peduncles of the cerebellum.

4. The ninth pair of cranial nerves, the Glossopharyngeal, leave the ventral side of the medulla by several roots. (Plate VII., A.)

5. The tenth pair of cranial nerves, the Vagus, or Pneumogastric, arise just posterior to the ninth, by several roots. (Plate VII., A.)

6. The eleventh pair of cranial nerves, the Spinal Accessory, arise by a series of roots from the sides of the spinal cord and medulla oblongata. They run anteriorly and enter the cavity of the skull. (Plate VII., A.)

7. The twelfth pair of cranial nerves, the Hypoglossal, arise by several roots from the ventral surface of the medulla, between the anterior pyramids and the olivary bodies. (Plate VII., A.)

\section{INTERNAL ANATOMY OF THE BRAIN.}

Slice off the upper part of the right hemisphere to a level with the corpus callosum.

I. The Gray Matter will be seen as a narrow, convoluted, cortical layer, surrounding the inner or medullary portion, the White Matter. (Plate VII., в.)

2. The Corpus Callosum can now be more clearly seen and its fibres traced into the cerebral lobes. 
Carefully remove the corpus callosum and expose the cavity below.

3. The Lateral Ventricles are the two irregularshaped cavities, extending below the corpus callosum, through the greater part of each hemisphere. The anterior portion of the ventricle, which is continued forward and downward into the anterior part of the hemisphere, is the anterior cornu. The continuation of the ventricle backward and downward forms the descending cornu, while the reduced posterior part is the posterior cormu. (Plate VII., B.)

4. The Septum Lucidum is the partition separating the anterior cornua of the two lateral ventricles.

5. The Corpus Striatum is the more or less oval mass, projecting into the cavity of the anterior cornu from its outer wall. (Plate VII., в.)

6. The Hippocampus Major is the large oval projection forming the floor of the posterior part of the lateral ventricle and descending cornu. Over its surface passes a thin vascular layer, the choroid plexus. (Plate VII., в.)

7. The Fornix is formed by two bands of fibres (the anterior pillars of the fornix), which pass dorsally from the corpora albicantia, and unite just under the anterior end of the corpus callosum. The triangular sheet formed by their union (the body of the fornix) lies immediately under the corpus callosum. Posteriorly it again divides into 
two diverging bands of fibres (the posterior pillars of the fornix), which pass out along the floor of the lateral ventricles between the corpus striatum and the hippocampus major. (Plate VII., B and c.)

Cut across the posterior pillars of the fornix and hippocampus major, and reflect them.

8. The Optic Thalamus is the rounded prominence immediately below the hippocampus major and the posterior pillars of the fornix. It lies just anterior to the corpora quadrigemina. The optic tracts pass over its lateral surface.

9. The Corpus Geniculatum is a small, prominent elevation, just posterior to the optic tract and between it and the corpora quadrigemina.

IO. The Foramen of Munro is a narrow, slit-like opening, lying between the descending pillars of the fornix and the optic thalamus. This passage, together with its fellow of the opposite side, forms a $Y$-shaped canal, connecting the two lateral ventricles with a median cavity, already mentioned, the third ventricle.

Remove the portion of the corpus callosum remaining between the posterior pillars of the fornix, being careful not to injure the dclicate membrane immediately below.

I I. The Velum Interpositum is the thin membrane forming the roof of the cavity (third ventricle) 
behind and below the body of the fornix. The margins of this membrane are very vascular, and are known as the choroid plexuses. These plexuses are continued through the foramina of Munro to form the choroid plexuses of the lateral ventricles. The velum is somewhat thickened posteriorly to form the pineal gland. (Plate VII., c.)

I 2. The Third Ventricle, before mentioned, is the very narrow cavity of the brain lying between the optic thalami. It is bounded above by the velum interpositum, and below by the lamina cinerea, corpora albicantia, crura cerebri, and the infundibulum, and with the cavity of the latter it is continuous. It opens anteriorly into the two lateral ventricles through the foramina of Munro. (Plate VII., c.)

Make a median, vertical, longitudinal section through the remaining portion of the brain.

I3. The Anterior Commissure is a delicate transverse band of fibres, passing between the two hemispheres, in front of the anterior pillars of the fornix. It connects the two corpora striata. The lamina cinerea passes between it and the optic chiasma. (Plate VII., c.)

I4. The Middle or Soft Commissure is a much larger band of transverse fibres and cells connecting the optic thalami. It passes across the upper part of the third ventricle. (Plate VII., c.)

I 5. The Posterior Commissure joins the dorsal por- 
tions of the optic thalami, and forms the posterior wall of the third ventricle, just in front of the corpora quadrigemina. (Plate VII., c.)

16. The Aqueduct of Sylvius is the narrow canal passing posteriorly from the third ventricle, beneath the corpora quadrigemina and above the crura cerebri. (Plate VII., c.)

I 7. The Fourth Ventricle is the cavity of the brain posterior to the aqueduct of Sylvius, bounded above by the valve of Vieussens and the cerebellum, and below and laterally by the medulla oblongata. It is continuous posteriorly with the central canal of the spinal cord. (Plate VII., c.)

I8. The Arbor Vitæ is the name given to the branching structure of white matter in the cerebellum. It is best seen in the section just made. (Plate VII., c.)

\section{DISTRIBUTION OF THE CRANIAL NERVES.}

I. The Olfactory Nerves (I.) are delicate fibres which arise from the olfactory lobes of the brain, pass through the ethmoid bone, and are distributed to the Schneiderian membrane of the nose.

2. The Optic Nerve (II.) passes through the optic foramen, and enters the posterior surface of the eyeball.

3. The Oculo-motor Nerve (III.) passes through the sphenoidal fissure of the skull, and is distributed to certain muscles of the eyeball (superior, inferior, 
and internal recti, and inferior oblique) and the levator muscle of the lid.

4. The Pathetic Nerve (IV.) passes through the sphenoidal fissure to another muscle (superior oblique) of the eyeball.

5. The Trigeminal Nerve (V.), soon after it emerges from the brain, enlarges into the Gasscrian ganglion. It then separates into three divisions: the ophthalmic, which passes through the sphenoidal fissure and is distributed to the lachrymal gland, upper lid, and conjunctiva of the eye, and the skin of the nose and forehead; the maxillary, which passes through the foramen rotundum and supplies the lower eyelid, side of the nose, upper teeth, and the roof of the mouth and pharynx; and the mandibular, which passes through the foramen ovale and supplies the muscles and skin of the side of the head, muscles of mastication, lower lip, teeth, salivary glands, and inside of the mouth.

6. The Abducens Nerve (VI.) passes through the sphenoidal fissure and supplies muscles of the eyeball.

7. The Facial Nerve (VII.) passes through the stylo-mastoid foramen and supplies the muscles of the face and head.

8. The Auditory Nerve (VIII.) enters the internal auditory meatus and is distributed to the internal ear.

9. The Glosso-pharyngeal Nerve (IX.) emerges 
from the jugular foramen of the skull, and is distributed to the root of the tongue, soft palate, and pharynx.

IO. The Vagus Nerve (X.) also emerges from the jugular foramen. It has two ganglia, one within the skull, at the point where it enters the foramen, and another, outside the skull, a short distance beyond the foramen. The nerve passes down the neck, between the internal jugular vein and the carotid artery, enters the thorax, and there passes along the œesophagus and posterior mediastinum. It sends branches to the following organs: pharynx, larynx, heart, lungs, œsophagus, stomach, liver, and spleen.

I I. The Spinal Accessory Nerve (XI.) passes anteriorly along the side of the spinal cord, enters the skull by the foramen magnum, and again emerges from the jugular foramen in two branches. One branch fuses with the vagus nerve at the first ganglion of the latter; the other branch is distributed to the sterno-mastoid and trapezii muscles.

I 2. The Hypoglossal Nerve (XII.) leaves the skull by the anterior condyloid foramen, passes back to the lower side of the digastric muscle, then forward above the hyoid bone to the under side of the tongue.

\section{SPINAL CORD.}

The Spinal Cord is the posterior continuation of the medulla oblongata, which lies in the neural 
canal of the spinal column. It is composed, as is the medulla, of an inner core of gray matter and of external columns of white fibres. A median longitudinal fissure extends along both the middorsal and mid-ventral lines. In the brachial and lumbar regions the cord becomes somewhat broadened, to form the cervical and lumbar enlargements. In the sacral region the cord ends in a small nerve-filament, the filum terminale. The filum terminale, together with the sacral nerves, which lie parallel with each other for some distance in the vertebral canal, form the cauda equina.

\section{SPINAL NERVES.}

The Spinal Nerves each arise from the spinal cord by a dorsal and ventral root, and pass out from the neural canal through an intervertebral foramen. The dorsal root bears a ganglion. After emerging from the neural canal, each nerve divides into a dorsal and ventral branch.

\section{A.-Brachial Plexus. (Plate VII., D.)}

The Brachial Plexus is the net-like arrangement formed by the union of the ventral divisions of the sixth, seventh, and eighth cervical and first thoracic nerves. Its branches supply the region of the shoulder and arm. The principal nerves arising from the brachial plexus are :

I. A small nerve, which supplies the rhomboideus muscle. 
2. The .Suprascapular Nerve, which supplies the supra- and infra-spinatus muscles.

3. Several Subscapular Nerves, which supply the subscapular, teres major, and latissimus dorsi muscles.

4. The Musculo-cutaneous Nerve, which supplies the biceps, the brachialis anticus, and coraco-brachialis muscles, and the skin of the outer side of the fore-leg below the elbow.

5. The Circumflex Nerve, which passes between the subscapular and teres major muscles, and supplies the deltoid and teres minor muscles and the skin of the shoulder.

6. The Musculo-spiral Nerve, which winds around the humerus and is distributed to the skin and muscles of the fore-leg.

7. The Median Nerve, which passes through the internal condyloid foramen and supplies muscles on the ventral side of the fore-leg.

8. The Ulnar Nerve, which is distributed to the muscles and skin of the fore-leg.

9. The Internal Cutaneous Nerve, which supplies the skin on the inner side of the fore-leg.

IO. The Anterior Thoracic Nerve, which supplies the pectoral muscles and part of the latissimus dorsi muscle.

\section{B.-Lumbar Plexus. (Plate VII., E.)}

The Lumbar Plexus is composed of the ventral divisions of the fourth, fifth, sixth, and seventh 
lumbar, and first sacral nerves. Its branches are distributed to the regions of the pelvis and hindleg. The principal nerves arising from the lumbar plexus are :

I. The Ilio-hypogastric Nerve, which supplies the skin of the abdomen.

2. The Ilio-inguinal Nerve, which supplies the skin of the inguinal region and external generative organs.

3. The Genito-crural Nerve, which passes beneath Poupart's ligament and supplies the skin of the thigh and the spermatic cord.

-4. The External Cutaneous Nerve, which also passes beneath Poupart's ligament and supplies the skin 'of the hip and thigh.

5. The Anterior Crural Nerve, which passes down the front of the thigh and supplies the skin and muscles of the thigh and leg.

6. The Obturator Nerve, which passes along the side of the pelvis and through the obturator foramen.

7. The Great Sciatic Nerve, the largest nerve of the body, which passes through the sacral sciatic notch, between the tuberosity of the ischium and the great trochanter of the femur, and then down the hind-leg to innervate the thigh, leg, and foot.

8. The Lesser Sciatic Nerve, which supplies the muscles of the back of the hip and thigh.

9. The Caudal Nerve, which runs down the side of the tail and supplies its muscles. 


\section{SYMPATHETIC SYSTEM.}

The Sympathetic Nervous System consists, first, of a delicate, double chain of ganglia, extending along the ventral side of the spinal column from the head to the tail, and, secondly, of numerous branches and ganglia throughout the body. The branches of both divisions are distributed to the viscera and blood-vessels. In the head they communicate with many of the cranial nerves, and in the trunk with the spinal nerves.

In the thorax the two sympathetic cords may be seen lying along the line of the heads of the ribs, between the pleura and intercostal bloodvessels. In the lumbar region the cords lie nearer together on the bodies of the vertebræ, at the inner margins of the psoas muscles. In the sacral region the cords unite in a single ganglion.

There are three plexuses of nerves and ganglia connected with the sympathetic system :

I. The Cardiac Plexus lies at the base of the heart on the aorta and pulmonary artery. It receives branches from the vagus and cervical sympathetic ganglion, and innervates the heart.

2. The Solar Plexus lies between the adrenal bodies, stomach, aorta, and crura of the diaphragm. It receives branches from the vagus, cardiac plexus, and sympathetic cords, and sends nerves to the abdominal viscera. 
3. The Hypogastric Plexus lies between the right and left iliac arteries. It receives branches from the solar plexus and lumbar part of the sympathetic cords, and sends branches to the pelvic viscera. 


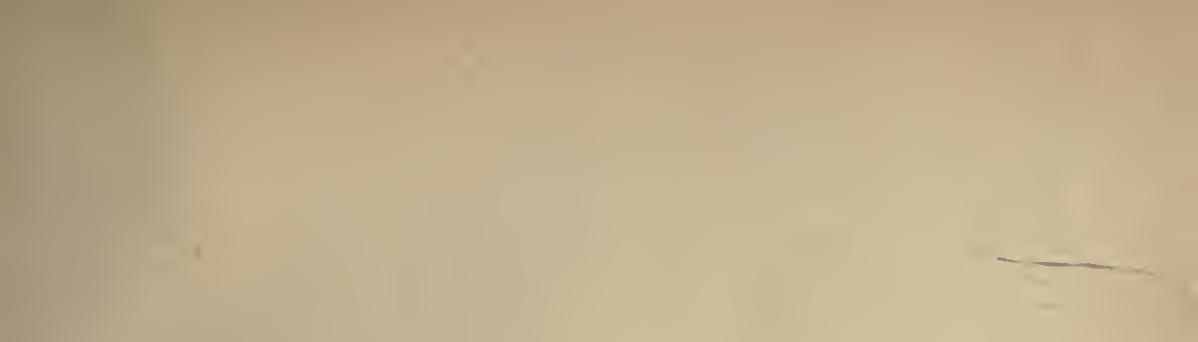

$$
\text { . }
$$




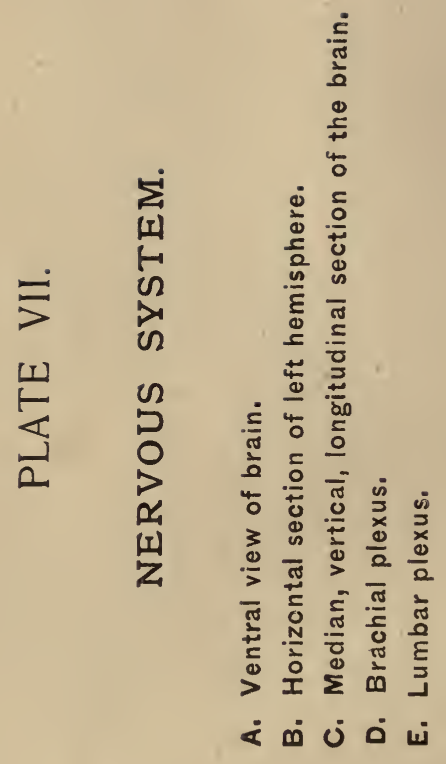




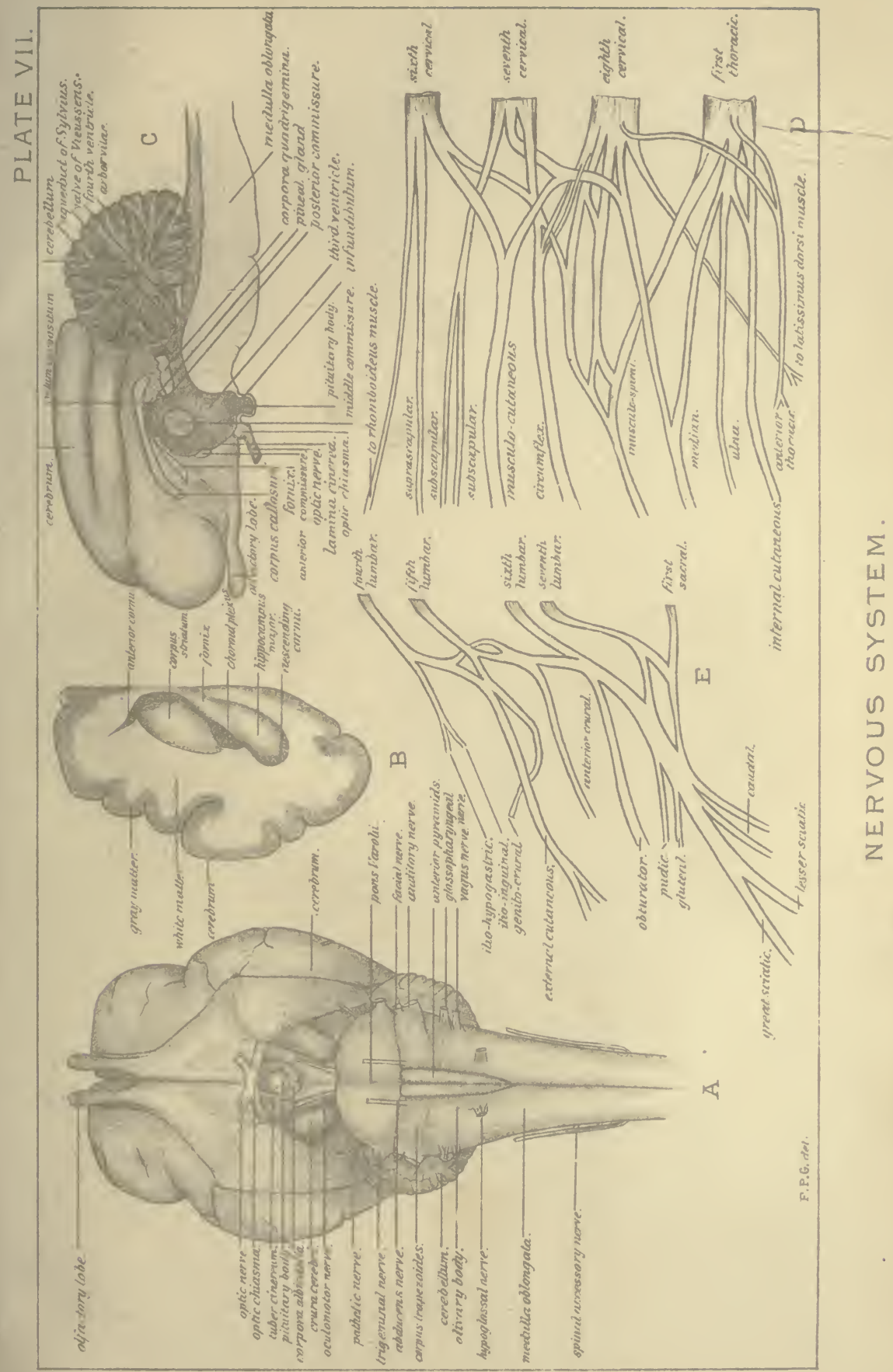





\section{CHAPTER VI}

\section{EYE}

\section{APPENDAGES OF THE EYE.}

I. The Eyelids are two folds of skin, one dorsal, one ventral, which guard the anterior portion of the eyeball. There are no "eyelashes," but the whole external surface of the lid is covered with hair. The inner surface of the lid is covered with mucous membrane, which is continuous over the front of the eyeball, and is known as the conjunctiva. The angles where the two eyelids meet are known respectively as the inner canthus and outer canthus of the eye.

2. The Puncta Lachrymalia are two small openings situated on each eyelid a short distance from the inner canthus. They open into two lachrymal canals, which unite to form the lachrymal duct, which opens into the nasal cavity.

3. The Meibomian Glands are the parallel rows of yellowish glands situated on the inner surface near the edge of each lid.

4. The Nictitating Membrane, or "third eyelid," is a large fold of membrane arising from the inner canthus of the eye, between the lids and the eye- 
ball. It consists of folds of conjunctiva, strengthened by a cartilage at its free margin.

5. The Harderian Gland is a small gland situated on the nictitating membrane.

6. The Lachrymal Gland lies in the upper and outer part of the orbit, between the wall of the orbit and the eyeball. Its duct opens on the inner surface of the upper eyelid, just above the outer canthus.

Remove the zygomatic arch and the underlying muscles, cut away the coronoid process of the mandible, and cxpose the lateral surface of the eyeball, being careful not to disturb its attachment.

7. The External Rectus Muscle of the eyeball arises from the wall of the orbit just external to the optic foramen. It is inserted on the outer (lateral) surface of the eyeball.

8. The Inferior Rectus Muscle arises from the ventral margin of the optic foramen, and is inserted on the ventral side of the eyeball.

9. The Inferior Oblique Muscle arises from the orbital process of the maxillary bone, and is inserted on the eyeball, on its ventral and outer side, along the edge of the external rectus muscle.

Io. The Internal Rectus Muscle arises from the inner margin of the optic foramen and is inserted on the inner side of the eyeball.

I I. The Superior Rectus Muscle arises from the 
dorsal margin of the optic foramen and is inserted on the dorsal surface of the eyeball.

I2. The Superior Oblique Muscle arises from the margin of the optic foramen. Nearly opposite the middle of the eyeball it becomes tendinous, and passes through a fibro-cartilaginous ring, situated on the inner dorsal side of the orbit; it then passes toward the eyeball and is inserted on the dorsal side, at right angles to the insertion of the superior rectus muscle.

I 3. The Choanoid Muscles arise around the optic foramen and are inserted on the circumference of the eyeball, within the insertion of the recti muscles.

\section{EYEBALL。}

Remove the eyeball from the orbit by cutting through the muscles and optic nerve. Dissect off the fat and other tissues adhering to its surface.

I. The Sclerotic Coat is the white, opaque portion of the external coat of the eye. It is pierced by the optic nerve, near the middle point of its posterior surface. The sclerotic coat is composed of smooth, white, fibrous tissue, and gives solidity to the eyeball.

2. The Cornea is the transparent anterior portion of the external coat. Its outer surface is covered by the conjunctiva. 
Divide the eye into an anterior and posterior half.

3. The Vitreous Humor is the transparent, jellylike mass filling the posterior chamber of the eye, which has now been exposed.

4. The Retina is the innermost of the three coats of the eye. It is a delicate membrane formed by the expansion of the optic nerve on the interior of the eye. The optic disc, or blind spot, is the small, white, round area at the point where the optic nerve pierces the sclerotic and choroid coats and expands into the retina. The blood-vessels supplying the retina radiate from the blind spot.

5. The Choroid is the thin coat of the eye lying between the sclerotic and the retina. It is of a dark color, owing to the pigment which is everywhere present, except in a circular area on the back of the choroid, around and above the entrance of the optic nerve. This spot is of a lighter color, and is known as the tapetum.

6. The Ciliary Processes are the irregular folds into which the choroid is thrown at the margin of the cornea.

7. The Ora Serrata is the anterior toothed margin of the retina. It lies around the periphery of the ciliary processes.

8. The Crystalline Lens is a transparent, double convex body, situated in front of the vitreous humor. It is more convex anteriorly than poste- 
riorly. The lens is enveloped in a thin, transparent membrane, known as the capsule of the lens.

9. The Suspensory Ligament is a very delicate membrane attached to the capsule at the edge of the lens. It suspends the lens from the ciliary processes.

IO. The Ciliary Muscle is a ring of radiating muscular fibres, arising from the sclerotic at the edge of the cornea and passing backward to the choroid opposite the ciliary processes. By its contraction the lens is made more convex.

II. The Iris is the anterior portion of the choroid. It forms a perforated circular disc at the front of the crystalline lens. The perforation is known as the pupil.

I 2. The Aqueous Humor is the fluid filling the anterior chamber of the eye, between the lens and the cornea. 



\section{INDEX}

A

Abdomen, muscles of, 28

Abdominal cavity, 14, 30 viscera, 14

Abduceus nerve, 59, 66

Acetabulum, 12

Acromio-deltoid muscle, 34

Acromion process, II

Adductor muscle, 42

Adrenal bodies, 18

Alimentary canal, I4

Anal glands, I7

Anconeous muscle, 38

Ankle, I3

Anterior condyloid foramen, 5

Anus, I6

Aorta, 2, 3, 45

Aponeurosis, vertebral, 32

Aqueduct of Sylvius, 65

Aqueous humor, 77

Arachnoid, 55

Arbor vita, 65

Arterial system, 45

Arteries, anterior circumflex, 47

anterior tibial, 50

axillary, 47

basilar, 46

brachial, 47

brachio-cephalic, 45

bronchial, 48

caudal, 50

cœeliac axis, 48

coronary, 48

deep femoral, 49

dorsal of foot, 50

epigastric, 49

external iliac, 49

external plantar, 50

external pudic, 50

facial, 45

femoral, 49

gluteal, 50

hepatic, 48

ilio-lumbar, 49
Arteries, inferior mesenteric, 49

inferior profunda, 47

innominate, 45

intercostal, 48

internal iliac, 50

internal mammary, 46

internal plantar, 50

internal pudic, 50

left carotid, 45

lingual, 45

long thoracic, 47

muscular branch of carotid, 45

muscular branches, 50

obturator, 49

ovarian, 49

phrenic, 48

popliteal, 50

post-auricular, 46

posterior circumflex, 47

posterior tibial, 50

profunda, 49

pudic, 50

pulmonary, 23

radial, 47

renal, 49

right carotid, 45

right sub-clavian, 46

sciatic, 50

spermatic, 49

splenic, 48

sternal, 46

subscapular, 57

superior intercostal, 46

superior mesenteric, 48

superior profunda, 47

superior thoracic, 47

superior vesical, 50

suprarenal, 48

temporal, 46

thyroid, 45

thyroid axis, 46

ulna, 47

vertebral, 46

Arytenoid cartilages, 26

Astragalus, I 3 
Atlas, 9

Atrium of heart, 22

Auditory bulla, 5 meatus, 5 nerve, 60,66

Auricles, 22

Auricular appendix, 22

Axillary artery, 47

Axis, 9

Azygos vein, 5 I

Basi-hyal bone, 8

Basilar artery, 46

Biceps femoris muscle, 39 muscle, 37

Bile-duct, 16

Bladder, I 8

Blind spot, 76

Bones, astragalus, 13

basi-hyal, 8

calcaneum, $\mathrm{r}_{3}$

carpal, I3

cerato-hyal, 8

chevron, 9

clavicle, ro

epi-hyal, 8

ethmoid, 7

femur, 13

fibula, I 3

frontal, 6

humerus, II

hyoid, 8

ilium, I2

innominate, 12

interparietal, 6

ischium, 12

lachrymal, 7

malar, 6

mandible, 7

maxillary, 7

metacarpal, I 2

metatarsal, 13

nasal, 7

occipital, 5

palatine, 7

parietal, 6

patella, 13

phalanges, $\mathrm{x} 2$

pollex, I 2

premaxillary, 7

presphenoid, 6
Bones, pubis, 12

radius, II

ribs, Io

scapula, ro

sphenoid, 6

sternum, Io

stylo-hyal, 8

tarsal, I3

temporal, 5

thyro-hyal, 8

tibia, I 3

turbinated, 7

ulna, II

vertebræ, 8, 9

vomer, 7

Brachial artery, 47

plexus, 68

Brachialis anticus muscle, 37

Brachio-cephalic artery, 45 vein, $5 \mathrm{I}$

Brain, external anatomy, 56 internal anatomy, 6r preparation of, I

Bronchi, 2I

Bronchial arteries, 48

Buccal glands, 24

Bulla, auditory, 5

C

Cxcum, I6

Calcaneum, $\mathrm{r}_{3}$

Canine teeth, 7,8

Canthus of eye, 73

Capsule of lens, 77

Caput epididymis, 19

Cardiac plexus, 7I

Carotid artery, 45

Carpal bones, 12

Cartilage, costal, Io ensiform, Io tympano-hyal, 8

Cauda epididymis, I 9 equina, 68

Caudal artery, 50 nerve, 70 vein, 54 vertebræe, 8,9

Cephalo-humeral muscle, 30, 32

Cerato-hyal bone, 8

Cerebellum, 56, 59

Cerebral hemispheres, 56

Cerebrum, 56 
Cervical vertebra, 8, 9

Chevron bones, 9

Choanoid muscle, 75

Chordæe tendinæe, 22

Choroid, 76 plexus, 64

Ciliary muscle, 77 processes, 76

Circumflex arteries, 47 nerve, 69

Circumvallate papillæe, 25

Clavicle, Io

Cleido-mastoid muscle, 33

Clitoris, 20

Coeliac axis, 48

Colon, 15

Columnx carnex, 22

Commissures of brain, 64

Condyles, occipital, 5 of femur, 13

Condyloid foramina, 5

Conjunctiva, 73

Coraco-brachialis muscle, 37

Cornea, 75

Cornua of lateral ventricles, 62

Corocoid process, II

Coronary artery, 23, 48 vein, 22

Coronoid process, 8 , II

Corpora albicantia, 58

cavernosa, 20 quadrigemina, 57

Corpus callosum, 57,61 geniculatum, 63 spongiosum, 20 striatum, 62 trapezoides, 60

Costal cartilages, Io

Cowper's glands, I9

Cranial nerves, $56-61,65$

Cricoid cartilage, 26

Crura cerebri, $5 \mathrm{~S}$ of cerebellum, 56,59 of diaphragm, 30 penis, 20

Crural nerve, 70

Crystalline lens, 76

Cutaneous nerves, 69,70

Cystic duct, I 7

1)

Deltoid ridge of humerus, I I Dental formula, 8
Diaphragm, 30

Digastric muscle, 43

Dorsal artery of foot, 50 vertebræ, 8, 9

Duct, cystic, 17 lachrymal, 73 Stenson's, 23

Wharton's, 24

Duodenum, 15

Dura mater, 55

E

Ear, 25

Ensiform cartilage, Io

Epididymis, I9

Epigastric artery, 49

Epiglottis, 26

Epi-hyal bone, 8

Epitrochlear muscle, 35

Erector spinæe muscle, 32

Ethmoid bone, 7

Eustachian tubes; 25

External oblique muscle, 28

Eye, 2, 73

Eyeball, 75

Eyelids, 73

F

Facial artery, 45 nerve, 60,66 vein, $5 \mathrm{I}$

Falciform ligament, I6

Fallopian tubes, 20

Falx cerebri, 55

Femoral artery, 49

Femur, I3

Fibula, 13

Filiform papillæ, 25

Filum terminale, 68

Fissure, sphenoidal, 6

Foramina, anterior condyloid, intervertebral, 9 jugular, 6 magnum, 5 obturator, I 2 of Munro, 63 optic, 6 ovale, 6 rotundum, 6 stylo-mastoid, 5 supra-condyloid, I I 
Formalin, I.

Fossa, glenoid, 6 infraspinous, II olecranon, II subscapular, II supraspinous, II temporal, 6

Frontal bone, 6

Fundus, I4

Fungiform papillæ, 25

\section{G}

Gall-bladder, I 7

Ganglia of spinal nerves, 68

Gasserian ganglion, 66

Genio-hyoid muscle, 43

Genito-crural nerve, 70

Glands, anal, $\mathbf{I} 7$

buccal, 24

Cowper's, 19.

Harderian, 74

lachrymal, 74

lymph, I 7

Meibomian, 73

parotid, 23

pineal, 57,64

prostate, 19

salivary, 23

sublingual, 24

submaxillary, 24

thymus, 21

thyroid, 27

zygomatic, 24

Glans penis, 20

Glenoid cavity, II fossa, 6

Glosso-pharyngeal nerve, 6r, 66

Glottis, 26

Gluteal artery, 50

Glutei muscles, 39,40

Gracilis muscle, 4I

Gray matter of brain, 6I

Gyri, 56

$\mathrm{H}$

Hallux, 13

Harderian gland, 74

Heart, 2, 21, 22

Heel, bone of, 13

Hemispheres of cerebellum, 59 of cerebrum, 56

Hepatic artery, 48 vein, 53
Hilus of kidney, 18

Hippocampus major, 62

Humerus, II

Hyoid arch, 8

Hypogastric plexus, 72

Hypoglossal nerve, 6r, 67

I

Ileum, 15

Iliac arteries, 49, 50 veins, 53

Ilio-hypogastric nerves, 70 inguinal nerve, 70 lumbar artery, 49 lumbar vein, 53

Ilium, I 2

Incisor teeth, 7, 8

Infraspinatus muscle, 35

Infraspinous fossa, II

Infundibulum, 58

Inguinal canal, I 9, 29

Injection, I mass, I

Innominate artery, 45 bones, 12 veins, $5 \mathrm{I}$

Instruments, I

Intercostal arteries, 48 muscles, 32

Internal mammary artery, 46 oblique muscle, 29

Interparietal bone, 6

Intervertebral foramen, 9

Intestine, 15

Iris, 77

Ischium, 12

Jaws, 7

Jejunum, I5

Jugular foramen, 6 veins, $5 \mathrm{I}, 52$

\section{K}

Kidneys, I7

L

Lachrymal bones, 7 canals, 73

duct, 73

gland, 74 
Lambdoidal ridge, 5

Lamina cinerea, $5^{8}$

Large intestine, $\mathrm{I}_{5}$

Larynx, 8, 24, 26

Latissimus dorsi muscle, 33,36

Lens, 76 capsule of, 77

Levator anguli scapulæ muscle, 36 claviculæ musċie, 34

Linea alba, 28 aspera, I 3

Lingual artery, 45

Liver, I6

Lumbar plexus, 69 vertebræ, 8,9

\section{Lungs, 21}

Lymphatics, 15

Lymph glands, I 7

\section{M}

Malar bones, 7 process, 7

Mandible, 7

Mandibular nerve, 66

Manubrium, Io

Masseter muscle, 44

Maxillary bones, 7 nerve, 66 vein, 5 I

Meatus, external auditory, 5

Median nerve, 69

Mediastinum, 20

Medulla oblongata, 56,60

Meibomian glands, 73

Mesenteric arteries, 48, 49

Mesentery, 15

Metacarpal bones, I2

Metacromion process, II

Metatarsal bones, I 3

Mitral valve, 23

Molar teeth, 7,8

Mouth, 24

Munro, foramen of, 63

Muscles, 28

Muscles, acromio-deltoid, 34 adductor, 42 anconeus, 38 anterior trapezius, 32 biceps, 37

biceps femoris, 39 brachialis anticus, 37

cephalo-humeral, 30, 32
Muscles, choanoid, 75

ciliary, 77

cleido-mastoid, 33

coraco-brachialis, 37

digastric, 43

epitrochlear, 35

erector spinæ, 32

external intercostal, 32

external oblique, 28

external rectus, 74

genio-hyoid, 43

glutei, 39, 40

gracilis, $4 \mathrm{I}$

inferior oblique, 74

inferior rectus, 74

infraspinatus, 35

internal intercostal, 32

internal oblique, 29

internal rectus, 74

latissimus dorsi, 33, 36

levator anguli scapulæ, 36

levator claviculæ, 34

masseter, 44

middle trapezius, 33

mylo-hyoid, 43

of abdomen, 28

of fore-leg, 32

of hind-leg, 39

of neck, 42

of shoulder, 32

of thigh, 39

of thorax, 30

pectineus, 42

pectoralis, 30, 33

polygastric, 29

posterior trapezius, 33

psoas magnus, 42

pyriformis, 4I

quadratus femoris, 40

quadriceps extensor, $4 \mathbf{I}$

rectus abdominis, 29

rectus femoris, $4 \mathrm{I}$

rhomboideus capitis, 34

rhomboideus major, 34

sartorius, 39

scaleni, 3I

semimembranosus, 40

semitendinosus, 40

serratus magnus, 36

serratus posticus, 32

spino-deltoid, 34

splenius, 44

sternalis, $3 \mathrm{I}$ 
Muscles, sterno-hyoid, 43 sterno-mastoid, 42 sterno-thyroid, 43 subscapularis, 36 superior oblique, 75 superior rectus, 74 supraspinatus, 35 temporalis, 44 tensor vaginæe femoris, 39 tenuissimus, 39 teres major, 35 teres minor, 36 thyro-hyoid, 43 transversalis abdominis, 29 trapezii, 32, 33

triceps, 37 vasti, 4 I

Muscular branches of arteries, 50 branch of carotid, 45

Musculo-cutaneous nerve, 69

Musculo-spiral nerve, 69

Mylo-hyoid muscle, 43

\section{$\mathrm{N}$}

Nares, 25

Nasal bones, 7

Nates, 57

Nerves, 56 abduceus, 59, 66 anterior crural, 70 anterior thoracic, 69 auditory, 60,66 caudal, 70 circumflex, 69 cranial, 56-6I, 65 external cutaneous, 70 facial, 60,66 genito-crural, 7o glosso-pharyngeal, 6I, 66 great sciatic, 70 hypoglossal, 61, 67 ilio-hypogastric, 70 ilio-inguinal, 70 internal cutaneous, 69 lesser sciatic, 70 mandibular, 66 maxillary, 66 median, 69 musculo-cutaneous, 69 musculo-spiral, 69 obturator, 70 oculomotor, 58,65
Nerves, olfactory, 56,65 ophthalmic, 66 optic, 57,65 pathetic, 58, 66 pneumogastric, 6I spinal, 68 spinal accessory, 61, 67 subscapular, 69 suprascapular, 69 sympathetic, 7I trigeminal, 59, 66 ulnar, 69 vagus, 61,67

Nervous system, 55

Neural arch, 8 canal, 8 process, 8

Nictitating membrane, 73

\section{$\mathrm{O}$}

Oblique muscle of eyeball, 74,75

Obturator artery, 49

foramen, 12 nerve, 70

Occipital bone, 5 condyles, 5

Oculomotor nerve, 58,65

Odontoid process, 9

(Esophagus, I4, 21, 26

Olecranon fossa, II process, I I

Olfactory lobes, 56 nerves, 56,65

Olivary body, 60

Omentum, I4

Ophthalmic nerve, 66

Optic chiasma, 57

disk, 76

foramina, 6

nerves, 57,65

thalamus, 63

Ora serrata, 76

Oral cavity, 25

Orbits, 7

Os penis, 20

Ovarian arteries, 49 veins, 53

Ovaries, 20<smiles>[3H]</smiles>

Pancreas, 16

Aselli, 17 
Palate, 24

Palatine bones, 7

Palmar arch, 49

Parietal bones, 6

Parotid gland, 23

Patella, I3

Pathetic nerve, 58,66

Pectineus muscle, 42

Pectoralis muscle, 30,33

I'eduncles of cerebellum, 59

P'elvic-girdle, 12

Pelvis, 9, I 2 of kidney, I8

l'enis, I9

Pericardium, 22

Peritoneum, I4

Phalanges, I 2, I3

Pharyngeal cavity, 25

Pharynx, 21, 24, 25

Phrenic artery, 48

Phrenic vein, 53

I'ia mater, 55

I'ig, 2

Pillars of fornix, 62

Pineal gland, 56, 64

Pituitary body, 58

Plantar artery, 50

Platysma myoides, 28

Pletira, 2 I

Plexus, brachial, 68

cardiac, $7 \mathrm{I}$

choroid, 64

hypogastric, 72

lumbar, 69

solar, $7 \mathrm{I}$

Pneumogastric nerve, 6r, 67

Pollex, I2

Polygastric muscle, 29

Pons Varolii, 56, 59

Popliteal artery, 50

Portal system, 54

Portal vein, 54

Postauricular artery, 46

Post-cava, 53

Post-orbital process, 6

Poupart's ligament, 28

Prie-cava, 5I

Premaxillary bones, 7

Premolar teeth, 7, 8

Prepuce, 20

Presphenoid bone, 6

Processes, acromion, II ciliary, 76
Processes, corocoid, II

coronoid, S, I I

malar, 7

metacromion, II

neural, 8

odontoid, 9

olecranon, II

post-orbital, 6

transverse, 8

zygomatic, 6

Profunda arteries, 47, 49

Prostate gland, I9

Psoas magnus muscle, 42

Pubis, I2

Pudic artery, 50

Pulmonary artery, 23

vein, 23

Puncta lachrymalia, 73

Pupil, 77

Pylorus, 15

Pyramid of kidney, I8

Pyramids, anterior, of cerebellum,

59

posterior, of medulla, 60

Q

Quadratus femoris muscle, 40

Quadriceps extensor muscle, 4I

$\mathrm{R}$

Radial artery, 47

Radius, II

Rectum, I6

Rectus abdominis muscle, 29

femoris muscle, $4 \mathrm{I}$

muscles of eyeball, 74

Renal arteries, 49 veins, 53

Reproductive system, I 8

Restiform bodies, 6I

Retina, 76

Rhomboideus capitis muscle, 34

Ribs, Io major muscle, 34

$\mathrm{S}$

Sacral vertebræ, 8,9

Salivary glands, 23

Sartorius muscle, 39

Scaleni muscles, 3 I

Scapula, Io 
Schneiderian membrane, 26

Sciatic arteries, 50 nerves, 70

Sclerotic, 75

Scrotal såc, I8

Semilunar valves, 23

Semi-membranosus muscle, 40

Semi-tendinosus muscle, 40

Septum lucidum, 62

Serous fluid, 22

Serratus magnus muscle, 36 posticus muscle, 32

Shoulder-blade, Io

Shoulder-girdle, Io

Skeleton, appendicular, ro axial, 5

Skull, 5

Small intestine, 15

Solar plexus, $7 \mathrm{I}$

Spermatic arteries, 49 cord, I9 veins, 53

Sphenoidal fissure, 6

Sphenoid bone, 6

Spigelian lobe of liver, I 7

Spinal accessory nerve, 6r, 67 column, 8 cord, 67 nerves, 68

Spine of scapula, to

Spino-deltoid muscle, 34

Spleen, I 7

Splenic artery, 48

Splenius muscle, 44

Stenson's duct, 23

Sternal artery, 46 veins, $5 \mathrm{I}$

Sternalis muscle, 31

Sternebræ, Io

Sterno-hyoid muscle, 43

Sterno-mastoid muscle, 42

Sterno-thyroid muscle, 43

Sternum, Io

Stomach, I4

Stylo-hyal bone, 8

Stylo-mastoid foramen, 5

Subclavian arteries, 46, 48 veins, 52

Sublingual glands, 24

Submaxillary gland, 24

Subscapular artery, 47

fossa, II

nerve, 69
Subscapularis muscle, 36

Sulci, 56

Superior intercostal artery, 46

Supracondyloid foramen, II

Suprarenal arteries, 48 veins, 53

Suprascapular nerve, 69

Supraspinatus muscle, 35

Supraspinous fossa, II

Suspensory ligament, 77

Sympathetic system, 7 I

Symphysis of jaw, 7

pubis, 12

\section{$\mathrm{T}$}

Tapetum, 2, 76

Tarsal bones, 13

Teeth, 7,8

Temporal artery, 46

bones, 5

fossa, 6

vein, $5 \mathrm{I}$

Temporalis muscle, 44

Tensor vaginæ femoris muscle, 39

Tentorium, 55

Tenuissimus muscle, 39

Teres major muscle, 35 minor muscle, 36

Testes, I 8 of brain, 57

Thoracic, anterior, nerve, 69

cavity, 30

long, artery, 47

superior, artery, 47

viscera, 2 I

Thorax, IO, 21

muscles of, 30

Thymus gland, 2 I

Thyro-hyal bone, 8

Thyro-hyoid muscle, 43

Thyroid artery, 45

axis, 46

cartilage, 26

glands, 27

Tibia, 13

Tibial arteries, 50

Toes, 13

Tongue, 25

Tonsils, 25

Trachea, 21, 27

Transversalis abdominis muscle, 29

Transverse processes, 8 vein, 52 
Trapezii muscles, 32,33

Triceps muscle, 37

Tricuspid valve, 22

Trigeminal nerves, 59, 66

Trochanter of femur, I3

Tuber cinereum, 58

Tuberosities of tibia, I3

Tuberosity of humerus, II of ischium, I2

Tunica albuginea, I9 vaginalis, I9

Turbinated bones, 7

Tympano-hyal cartilage, $s$

\section{$\mathrm{U}$}

Ulna, II

Ulnar artery, 47 nerve, 69

Ureter, I8

Urethra, I 8

Urinary system, I 7

Urino-genital canal, I9, 20

Uterus, 20

\section{V}

Vagina, 20

Vagus nerve, 6I, 67

Valve of Vieussens, 57

Valves, mitral, 23 semilunar, 23 tricuspid, 22

Vascular system, 45

Vas deferens, I9

Vasti muscles, 4I

Veins, azygos, $5 \mathrm{I}$ brachio-cephalic, $5 \mathrm{I}$ caudal, 54 common iliac, 53 coronary, 22 external jugular, $5 \mathrm{I}$

facial, $5 \mathrm{I}$

hepatic, 53

iliac, 53

ilio-lumbar, 53

inferior vena cava, 22, 53

innominate, $5 \mathrm{I}$

internal juguiar, 52

internal maxillary, $5 \mathrm{I}$

jugulars, $5 \mathrm{I}, 52$

ovarian, 53
Veins, phrenic, 53

portal, 54

post-cava, 53

præ-cava, 5 I

pulmonary, 23

renal, 53

spermatic, 53

sternal, 5I

subclavian, 52

superior vena cava, 22, $5 \mathrm{I}$

suprarenal, 53

temporal, 5I

transverse, 52

vena cava inferior, 22, 53

vena cava, superior, $22,5 \mathrm{I}$

vertebral, $5 \mathrm{I}, 52$

Velum interpositum, 63

Vena cava, inferior, 22, 53

superior, $22,5 \mathrm{I}$

Venous system, 5I

Ventricles of brain, 58, 62, 64, 65

of heart, 22, 23

Vermis of cerebellum, 59

Vertebræ, 8, 9

Vertebral aponeurosis, 32 artery, 46 column, 8 veins, $5 \mathrm{I}, 52$

Vesical, superior, artery, 50

Vestibule, 20

Vieussens, valve of, 57

Villi, I5

Viscera, I4*

abdominal, I4

of head, 23

of neck, 23

thoracic, 2 I

Vitreous humor, 76

Vocal cords, 26, 27

Vomer, 7

IV

Wharton's duct, 24

White matter of brain, 6I

Z

Zygomatic arch, 6

gland, 24

process, 6 






\section{$\checkmark$}

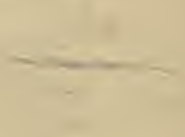

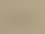




\section{DATE DUE SLIP}

UNIVERSITY OF CALIFORNIA MEDICAL SCHOOL LIBRARY

THIS BOOK IS DUE ON THE LAST DATE STAMIPED BELOW

\section{TMAR A 1936

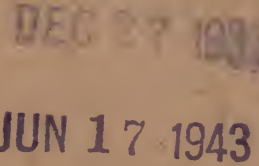

JUL 311943

APR 18 1945 AUG 2 ○ 1948

Nov $6-1950$ 


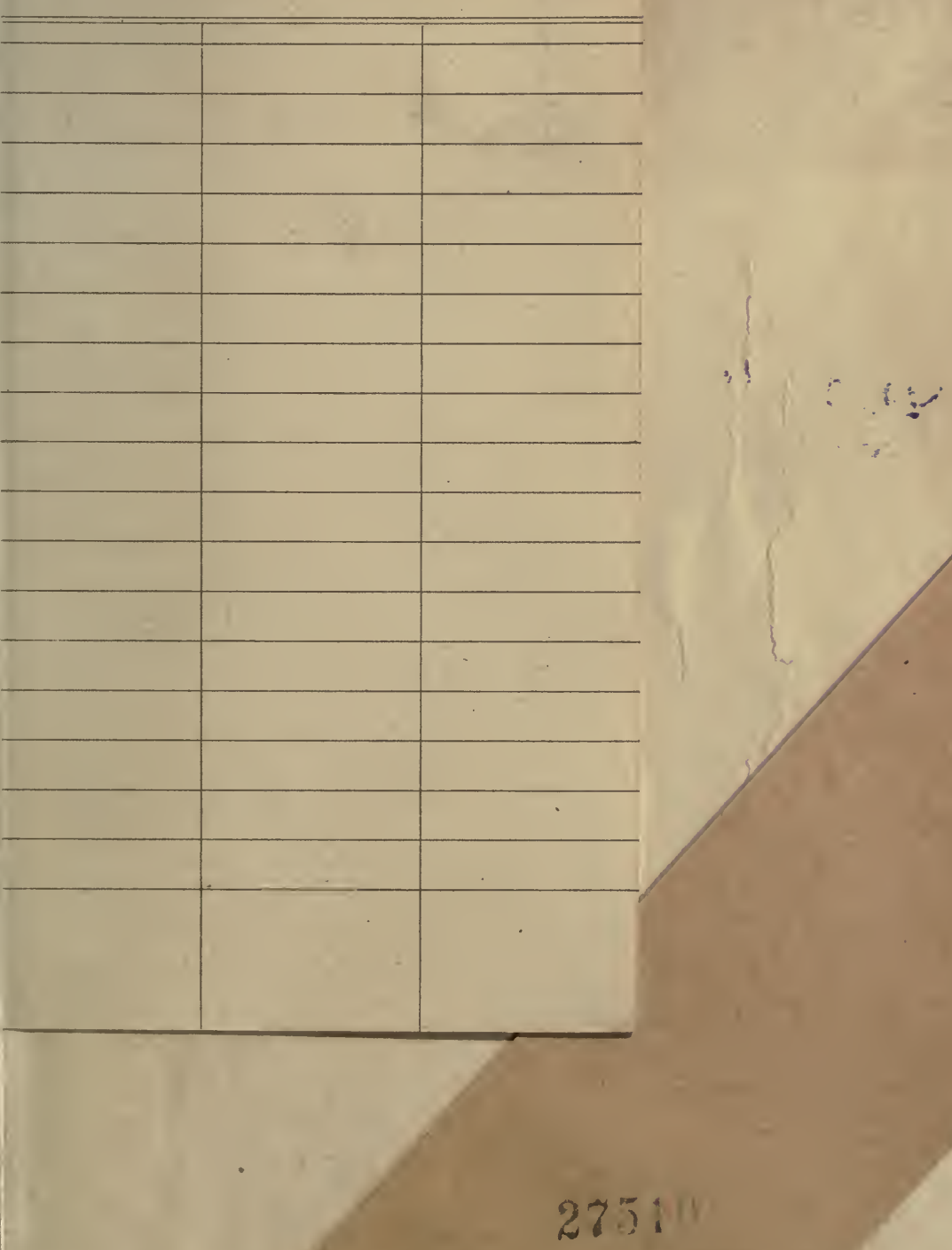




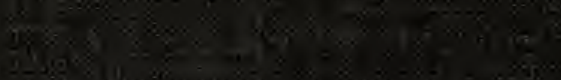

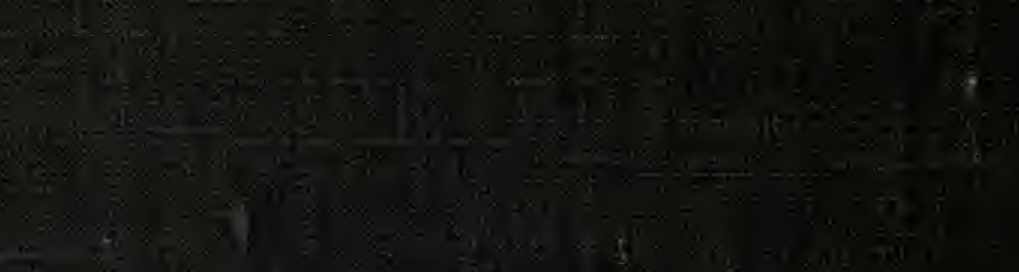

asis

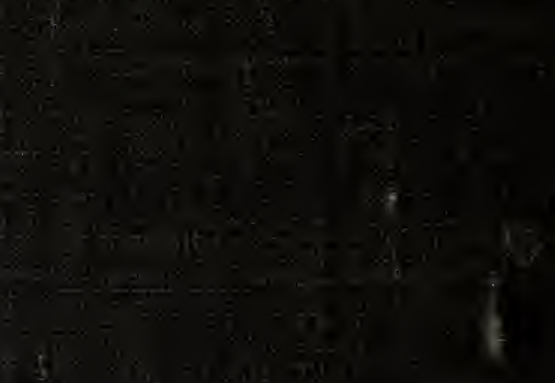

